\title{
Graphene synthesis and application for solar cells
}

\author{
Santanu Das \\ Department of Materials Science \& Engineering, Department of Mechanical \& Energy Engineering, \\ University of North Texas, Denton, Texas 76203 \\ Pitchaimuthu Sudhagar and Yong Soo Kang \\ WCU Program, Department of Energy Engineering, Center for Next Generation Dye-sensitized Solar Cells, \\ Hanyang University, Seoul 133-791, South Korea \\ Wonbong Choi $^{\text {a) }}$ \\ Department of Materials Science \& Engineering, Department of Mechanical \& Energy Engineering, \\ University of North Texas, Denton, Texas 76203
}

(Received 6 August 2013; accepted 19 September 2013)

\begin{abstract}
To date graphene and graphene-derived materials have created an immense research interests due to its extraordinary physical, chemical, and physiochemical properties, which delineated graphene as an outstanding material for future electronics, optics, and energy-harvesting devices. Typically, graphene has high mobility and optical transparency along with excellent mechanical properties and chemical inertness. Single-layer graphene exhibits ultrahigh optical transmissivity ( $\sim 98 \%)$, which allows passing through wide range of light wave lengths, thus designated as an ever-reported material for an optically conducting window. Furthermore, graphene's optical, electrical, and electrocatalytic properties can be tuned by applying different chemical functionalization protocols, which make it one of the most suitable candidates for advanced applications in optoelectronic and energy-harvesting devices. This review is intended to summarize the most important experimental results from the recent publications concerning the fascinating properties of graphene electrodes and their applications in various types of solar cells. Furthermore, the state of the art of different graphene synthesis processes and functionalization for the applications in solar cells are also discussed in this review.
\end{abstract}

\section{INTRODUCTION}

Graphene is a single atom, thick two-dimensional (2D) material, thus, exhibiting $\sim 97.7 \%$ transmittance throughout the entire visible light spectrum. Additionally, graphene has a flat transmittance spectrum from the ultraviolet (UV) region to the long wave length infrared (IR) region, thus exhibiting a wide window that allows a comprehensive range of photon wave length passed through it. Unconditionally, except graphene, these combinations of remarkable optical properties are yet to be observed in any types of materials till date. Similarly, graphene has unusual electronic transport properties, which follows the characteristics of 2D Dirac fermions, quantum hall effects, Landau level quantization, and so on. Consequently, graphene's free charges are immobile in one spatial dimension but mobile in other two dimensions, and thus, charge carrier mobility is $\sim 10^{6} \mathrm{~cm}^{2} / \mathrm{V} / \mathrm{s}$ in free-standing graphene. Similarly, graphene also exhibits excellent mechanical and thermal properties $(k \sim 3000-5000 \mathrm{~W} / \mathrm{mK})^{1}$

\footnotetext{
a) Address all correspondence to this author.

e-mail: Wonbong.Choi@unt.edu

DOI: $10.1557 /$ jmr.2013.297
}

and chemical inertness. Hence, all these properties coupled with the optical properties put together graphene a stronger candidate for applications in transparent conducting electrodes (TCEs), flexible optoelectronics, energyharvesting devices, photodetectors, and many other optical devices. Furthermore, graphene is anticipated as an emerging alternate for conventional transparent conductive metal oxides, specifically, indium tin oxide (ITO), which contains indium as a toxic, costly, and scarce element. In particular, the graphene-based TCE for application in solar cells with enhanced efficiency is of utmost interest.

To date, graphene electrodes have been applied for different types of solar cells, namely, solid-state solar cells, electrochemical solar cells, quantum dot solar cells (QDSCs), and polymer solar cells. The main advantages of applying graphene in different solar cells are: (i) it creates a window for inducing wide ranges (from UV to far IR regions) of photon energy inside the solar cells, (ii) it exhibits higher charge transfer (CT) kinetics at the interface of electrochemical hybrid cells, (iii) it manufactures a flexible device with robust architecture, and (iv) it provides greater heat dissipation. On the other hand, electrocatalytic activities of graphene play a key role in enhancing the efficiency of electrochemical solar cells 
like dye-sensitized solar cells (DSSCs), where the liquid/ solid interface acts as a pathway for transferring electrons. However, the inert nature of the graphene basal plane often holds back CT at the graphene/liquid interface despite the high in-plane charge mobility, so enhancement in electrocatalytic activities occurs only through the edge-planes. Hence, surface functionalization of graphene is required to improve in-plane CT and enhance application for electrochemical solar cells.

\section{AN OVERVIEW OF GRAPHENE SYNTHESIS}

The basic building blocks of all the carbon nanostructures are single graphitic layers, which are covalently $s p^{2}$ bonded carbon atoms that exist in a hexagonal honeycomb lattice (Fig. 1), which forms 3D bulk graphite, when the layers of single honeycomb graphitic lattices are stacked and bonded by a weak van der Waals force. The single graphite layer, when forms a sphere is known as zerodimensonal fullerene, when rolled up with respect to its axis forms a one-dimensional cylindrical structure, called the carbon nanotube, and when it exhibits a planar 2D structure from one to few layers stacked to each other, called graphene. ${ }^{2}$ One graphitic layer is known as single-layer graphene and correspondingly 2 and 3 graphitic layers are known as bilayer and trilayer graphene, respectively. More than 5 layers up to 10 layers graphene is generally called as few-layer graphene and $\sim 20$ to 30 layered graphene is characterized as multilayer graphene or thick graphene or nanocrystalline thin graphite. ${ }^{3}$

This section overviews the major and most popular graphene synthesis process, including exfoliation, chemical synthesis, thermal chemical vapor deposition (CVD), and epitaxial growth together with a brief discussion of their feasibility for applications in solar energy devices.

\section{A. Mechanical exfoliation}

Mechanical exfoliation belongs to a top down method in nanotechnology, by which a longitudinal or transverse stress is generated on the surface of the layered materials using simple scotch tape or atomic force microscopy (AFM) tip to strip off a single layer or few layers from the material. Although, mechanical exfoliation methods were attempted earlier in the year 1999 using AFM tips, however the process was unsuccessful to produce a single atom thick graphene layer. Novoselov et al. ${ }^{4}$ invented the special type of mechanical exfoliation process, by which they successfully synthesized a single atom thick graphene layer.

\section{B. Chemical exfoliation}

In chemical exfoliation process, alkali metal ions were used to intercalate the bulk graphite structure to separate out graphene layers followed by the dispersion in a solution. The main reasons for using alkali metals for

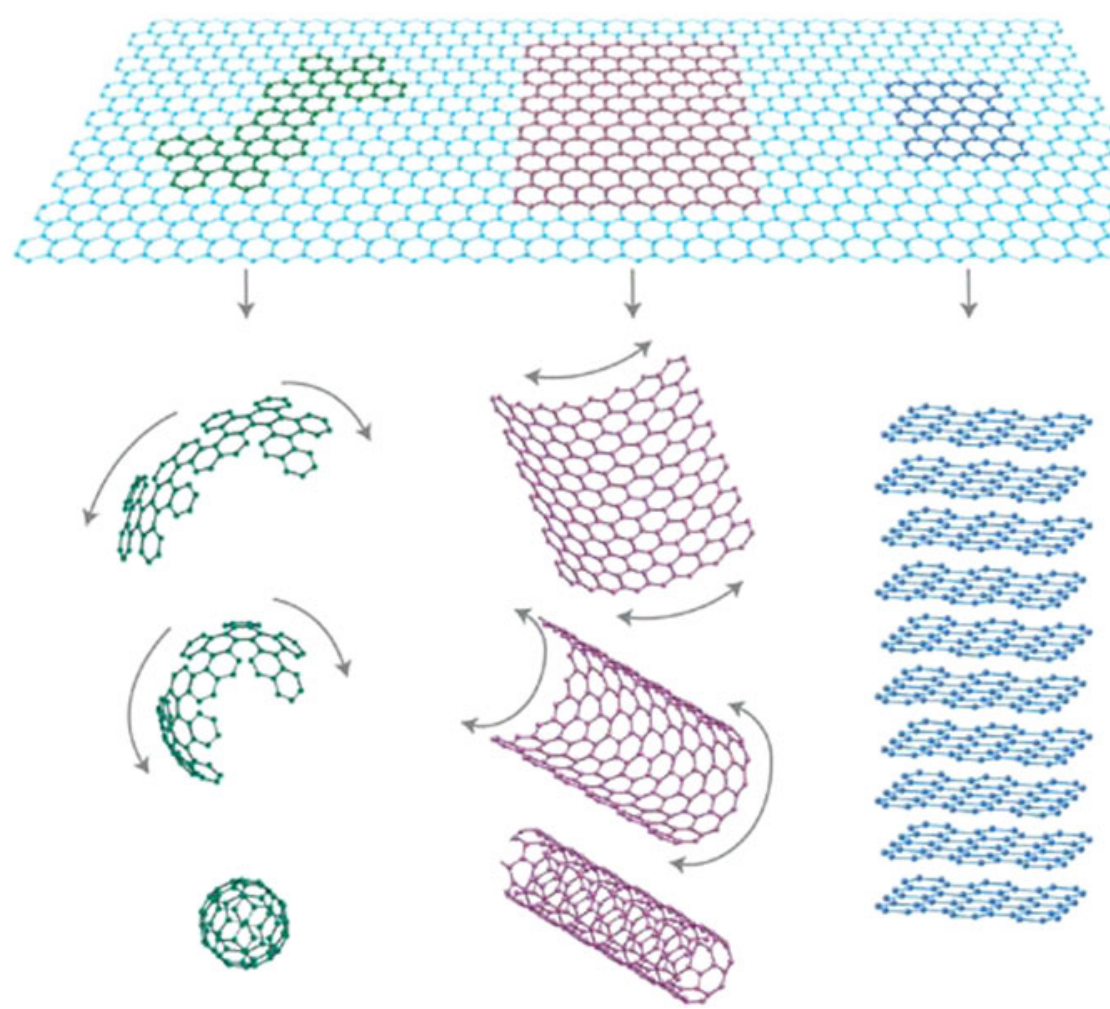

FIG. 1. The 2D hexagonal nanosheets of graphene as a building block of other forms of carbon nanomaterials. Reprinted with permission from Nature Publishing Group. ${ }^{2}$ 
intercalation reactions are as follows: (i) alkali metal ions can easily react with graphite and form intercalated structures, (ii) they also produce a series of intercalated compounds with different stoichiometric ratios of graphite to alkali metals, and (iii) alkali metals have their atomic radius smaller than the graphite interlayer distance and hence easily fit in the interlayer spacing during the intercalation reaction. The major types of alkali metal ions are $\mathrm{Li}, \mathrm{K}, \mathrm{Na}, \mathrm{Cs}$, and $\mathrm{Na}-\mathrm{K}_{2}$ alloy, which are commonly used to intercalate graphite for the chemical exfoliation process. ${ }^{5}$ Furthermore, the by-product of the exfoliation reaction, $\mathrm{KC}_{8}$, undergoes an exothermic reaction when reacting with the aqueous solution of ethanol $\left(\mathrm{CH}_{3} \mathrm{CH}_{2} \mathrm{OH}\right)$ as per Eq. (1).

$$
\mathrm{KC}_{8}+\mathrm{CH}_{3} \mathrm{CH}_{2} \mathrm{OH} \rightarrow 8 \mathrm{C}+\mathrm{KOCH}_{2} \mathrm{CH}_{3}+1 / 2 \mathrm{H}_{2} \text {. }
$$

Similarly, chemical exfoliation of graphene also demonstrated using the simple sonication process followed by the dispersion in organic solvents. ${ }^{6}$ Hernandez et al. ${ }^{6}$ reported the exfoliation of pure graphite in N-methylpyrrolidone using a straightforward sonication process, which yields high-quality unoxidized monolayer graphene.

\section{Chemical synthesis and functionalizations}

Chemical synthesis of graphene consists of few steps including the oxidation of graphite, dispersion of the graphene-oxide layers in a solvent, and reducing it back to graphene. The oxidation of graphite is carried out using the Hummer's method by reacting graphite with sodium nitrite, sulfuric acid, and potassium permanganate. ${ }^{7}$ The objective of transforming graphite into graphite oxide (GO) is to increase the interlayer spacing larger than the pristine graphite. In this regard, the interlayer spacing varies proportionally to the degree of oxidation reaction of graphite. Hence, this oxidized graphite further facilitates the dispersion of graphene in appropriate solvents. Graphene oxide is generally dispersed in a polar liquid medium, such as dimethylformamide (DMF), $\mathrm{N}$-methylpyrrolidone (NMP), dimethyl sulfoxide (DMSO), hexamethyl phosphoramide (HMPA), etc. After that, the dispersed GO is reduced back to graphene using dimethylhydrazine treatment at $80{ }^{\circ} \mathrm{C}$ for prolonged time. The homogeneity of GO dispersion strictly varies with the types of functional groups attached to graphene, which further hold back the graphene agglomeration in the solution. Thus, homogeneous dispersion causes the homogeneous reduction of GO with enhanced properties. Till date, several reports have been demonstrated on the application of GO for organic solar cells, ${ }^{8}$ DSSCs,${ }^{9,10}$ QDSCs, organic memory devices, ${ }^{11} \mathrm{Li}$ ion batteries, ${ }^{12}$ and many more. The primary advantages of the chemical synthesis process are low temperature and solution-based process, and therefore it possesses lots of flexibilities for scalability and direct synthesis of graphene film on various substrates. Additionally, in situ functionalization of graphene can be easily performed using this process for tuning of graphene's chemical and catalytic properties. However, the chemical synthesis process of graphene production has several shortcomings, such as (i) small yield, (ii) defective structure, and (iii) incomplete reduction of graphene, which readily degrade the graphene properties.

\section{Thermal CVD process}

Graphene can be synthesized on $\mathrm{Ni}$ and $\mathrm{Cu}$ using the CVD of hydrocarbon gases at high temperature in reduced atmospheric condition. In this process, $\mathrm{Cu}$ and $\mathrm{Ni}$ foils are used as substrates, where graphene deposition occurs on the surface of those transition metals due to the catalysis process. Several other metals such as $\mathrm{Pt}, \mathrm{Pd}, \mathrm{Ru}, \mathrm{Ir}, \mathrm{Co}$, and $\mathrm{Fe}$ are also used as substrates for the deposition of graphene by CVD. ${ }^{13}$ The process temperature was kept at $\sim 1000{ }^{\circ} \mathrm{C}$ (although several lower or higher temperature processes were reported as well) under reducing atmosphere $\left(\mathrm{H}_{2} \text { atmosphere }\right)^{3,14}$ to decompose methane $\left(\mathrm{CH}_{4}\right)$ and form graphene as per the following Eq. (2):

$$
\mathrm{CH}_{4}+\mathrm{H}_{2} \rightarrow \mathrm{C}+2 \mathrm{H}_{2} \quad \text {. }
$$

The process is versatile and scalable as the catalyzing process does not vary with the substrate size. Although large-scale graphene can be obtained by the CVD process, however, achieving large-scale homogeneous layer of graphene is still under challenge. Additionally, formation of grain boundaries and ripples in graphene during CVD processes causes defect formation in graphene. Hence, those defects create a major charge scattering and deteriorate graphene's electrical, thermal, and optical properties.

\section{E. Epitaxial growth}

The epitaxial growth process is performed for fabricating highly crystalline graphene onto single crystalline $\mathrm{SiC}$ substrates. Several reports demonstrated the growth of graphene through sublimation of Si from single-crystal $6 \mathrm{H}-\mathrm{SiC} .{ }^{15}$ The growth process includes the surface preparation using oxidation or $\mathrm{H}_{2}$ etching, followed by surface cleaning by bombarding electrons at $1000{ }^{\circ} \mathrm{C}$ at $\sim 10^{-10}$ Torr pressure under heat treatment at $1250-1450{ }^{\circ} \mathrm{C}$ for 1-20 min. This growth process is based on the Si sublimation mechanism at high temperature, which creates the anisotropy in graphene. ${ }^{16}$ Epitaxially grown graphene on $\mathrm{SiC}$ exhibits smaller and larger domain size based on the thermal decomposition method and different process parameters. ${ }^{17}$ Even, high-quality superior grade epitaxial graphene is obtained by this process, ${ }^{18}$ however, the transfer of graphene from $\mathrm{SiC}$ to other substrates is difficult, 
and the process cost is too high. Therefore, these seriously restrict the epitaxially grown graphene for solar cell applications.

\section{F. Graphene transfer}

Graphene transfer is a primary process for fabricating the graphene-based photovoltaic devices since graphene is synthesized in a dispersed solution form or a thin film on metal foils. To date, numerous processes have been demonstrated to transfer graphene on other substrates such as glass or flexible substrates. Some popular methods of graphene transfer from a dispersed medium to a substrate are drop-casting, spin coating, ${ }^{19,20}$ dip casting, ${ }^{20,21}$ and electrophoretic deposition. ${ }^{22}$ Additionally, few other methods, such as vacuum filtration, ${ }^{23}$ spraying, ${ }^{24}$ Langmuir-Blodgett assembly, ${ }^{25}$ and self-assembly methods,${ }^{26-29}$ are capable of transferring graphene on various transparent and flexible substrates. On the other hand, the graphene transfer processes from metal foils to other substrates are the chemical transfer process, ${ }^{30,31}$ PDMS transfer process,${ }^{32}$ hot press lamination process, ${ }^{33}$ stamping process,${ }^{34}$ and roll-to-roll transfer process. ${ }^{35}$

\section{G. Graphene as TCEs}

In conventional TCEs, controlling resistivity is one of the challenging tasks, which crucially depends on the two material parameters of high carrier concentrations ${ }^{36,37}$ and high carrier mobility. ${ }^{36}$ In practical, the conventional transparent conducting oxide (TCO) materials were possessing few demerits, such as complex structure, large band gap, and unavoidable charge scattering centers (arising from the presence of intrinsic dopants, defects, etc.), and were limiting their performance. In the context of searching highly TCEs with remarkable carrier mobility, monolayer graphene-based TCEs are becoming highly popular compared to conventional TCEs. The zero band gap property as well as carrier mobility (several orders higher than the traditional TCOs) offers wide applicability as TCEs in nanoelectronics. Furthermore, several simple and scalable techniques have been demonstrated for easy transfer of graphene on any polymer substrates, which is economically sound and technologically significant for flexible, transparent devices. Geim et al. reported that single-layer graphene exhibits $\sim 98 \%$ transparency and is the ever-reported transparent material found to date. However, transparency and sheet resistance decrease with increasing number of graphene layers as follows: bilayer graphene exhibits $95 \%$ transmittance and $1 \mathrm{~K} \Omega / \mathrm{sq}$ sheet resistance, trilayer graphene shows $\sim 92 \%$ transmittance and $\sim 700 \Omega /$ sq sheet resistance, and four-layer graphene possesses $\sim 89 \%$ transmittance and $\sim 400 \Omega /$ sq sheet resistance. $^{38}$ Wang et al. demonstrated the transparent graphene electrodes with $80 \%$ transparency, which is demonstrated as a TCO of DSSCs. Verma et al. ${ }^{33}$ reported the large-scale transfer of few layer graphene on polymer by using a simple hot press lamination method with $89 \%$ transparency. They demonstrated a simple and low cost hot press method, which was extended as large as $15 \times 5 \mathrm{~cm}$. Graphene on polymer film was utilized as anode for highresolution flexible field emission (FE) devices, where the flexible graphene showed recoverable electrical properties with stretching. Similarly, Lahiri et al..$^{39}$ also demonstrated the full transparent and flexible FE device comprised of both graphene-based cathode and anode. In this context, a roll-to-roll process has been demonstrated for the synthesis of large-scale (30 inch) graphene for touch screen applications. Bae et al. ${ }^{35}$ reported the transfer of single- to fourlayer graphene film on a polymer with transparency of 97 to $90 \%$, respectively. In the same report, it is found that the sheet resistance of the graphene film also varied from 275 to $50 \Omega /$ sq for single- to four-layer graphene.

\section{GRAPHENE FOR SOLAR CELLS}

\section{A. Graphene for solid-state solar cells}

To date, few reports have been found for graphene used as junction materials in solid-state solar cells. Although graphene is a near-zero band-gap material, due to the high mobility and electrical conductivity of graphene, the junction of graphene/n-type semiconductor heterojunction can be considered as an efficient Schottky junction. It is worth mentioning here that the work-function difference between graphene and the n-type semiconductor should be sufficient enough to create a built-in potential as shown in Fig. 2(a). Figure 2(a) shows the band diagram illustrating the mechanism of a graphene/n-type Schottky junction solar cell with a built-in potential of $\left(\varphi_{\mathrm{G}}-\varphi_{\mathrm{n}-\mathrm{Si}}\right)$. In this context, graphene- $\mathrm{Si}^{40}$ and graphene-single $\mathrm{CdS}$ nanowire $(\mathrm{NW})$ Schottky junction solar cells ${ }^{41}$ have been reported so far.

$\mathrm{Li}$ et al. first reported the graphene/n-Si solar cell, and the device structure is shown in Fig. 2(b). First, they created a trench by photolithographic patterning followed by etching away the $300-\mathrm{nm} \mathrm{SiO}_{2}$ layers from a wafer. Metal contacts were prepared using sputter deposition of $\mathrm{Ti} / \mathrm{Pd} / \mathrm{Ag}$ and $\mathrm{Au}$ on the backside and on the frontside of n-Si, respectively [Fig. 2(b)]. A few-layer CVD graphene was transferred over the pattern to prepare the graphene/n-type Si Schottky junction. The solar cell devices show an open circuit voltage $\left(V_{\mathrm{OC}}\right)$ of $0.42-0.48 \mathrm{~V}$, and a short-circuit current density $\left(J_{\mathrm{SC}}\right)$ of $4.0-6.5 \mathrm{~mA} / \mathrm{cm}^{2}$ with a power conversion efficiency (PCE) of $\sim 1.5 \%$ under the standard condition: air mass (AM) 1.5 global (1.5G) illumination of $100 \mathrm{~mW} / \mathrm{cm}^{2}$. Similarly, few other reports were found mentioning graphene/Si nanocrystal and graphene/Si nanopillar array Schottky junction solar cells, where the reported PCEs are about 0.02 and 1.96\%, respectively. In the same report, Feng et al. demonstrated a method of efficiency improvement of the graphene/Si nanopillar array Schottky junction solar cells by p-type 
doping of graphene using $\mathrm{HNO}_{3}$ treatment. The p-type doped graphene Schottky junction solar cells showed efficiency up to $3.55 \%$ using different dopant concentrations. Miao et al. $^{42}$ showed the enhancement of graphene/Si Schottky junction solar cell efficiency up to $8.6 \%$, which is the highest reported graphene-based solid-state solar cell efficiency. Here graphene is doped with bis(trifluoromethanesulfonyl)amide (TFSA), which act as a hole dopant in graphene increasing its work function without changing its optical properties. ${ }^{43}$ The dopinginduced graphene's chemical potential shift causes the carrier density increase in graphene as well as increase in the device's built-in potential and, thus, improves the solar cell fill factor and PCE up to $\sim 8.6 \%$. $^{42}$ In this regard, Ye et $\mathrm{al}^{41}$ reported a new type of Schottky junction solar cell using a junction of $\mathrm{CdS} \mathrm{NW}$ and/or CdS nanobelt (NB) with graphene. Figure 3(a) represents the schematic of Schottky junction formation in graphene-CdS. The CdS NW and CdS NB were synthesized by the CVD method and transferred them onto a $\mathrm{SiO}_{2} / \mathrm{Si}$ substrate as shown in the device architecture in Fig. 3(b). The device shows a PCE up to $1.65 \%$ (under AM $1.5 \mathrm{G}$ illumination) with corresponding $J_{\mathrm{SC}}, V_{\mathrm{OC}}$, and fill factor (FF) of $275 \mathrm{pA}$, $0.15 \mathrm{~V}$, and $40 \%$, respectively.

\section{B. Graphene-based DSSCs}

\section{Dye-sensitized solar cells}

The third generation photovoltaic devices including semiconductor quantum dots (SQD), ${ }^{44}$ organic photovoltaics (OPVs), ${ }^{45}$ and DSSCs ${ }^{46}$ find great attention in the photovoltaic research community. These new categories of photovoltaic devices are also appropriate in roll-to-roll fabrication and yield short energy payback time. In this part, we summarized the state of art on novel graphene-based materials for third generation PVs research including DSSCs, QDSCs, and OPVs.

Recently, DSSCs receive significant attention as promising embodiments in photovoltaic technologies for producing renewable, clean, and affordable energy. The low cost and the utilization of nontoxic components identify the DSSC as an ideal photovoltaic concept for integrated "green" architectures. In DSSCs, light absorption and charge transport are separated with charge carrier generation taking place in the chemisorbed self-assembled monolayer of sensitizer molecules sandwiched between the semiconducting anatase $\mathrm{TiO}_{2}$ (photoelectrode) and an electrolyte acting as electron- and hole-conducting materials, respectively [Fig. 4(a)]. The photoexcitation

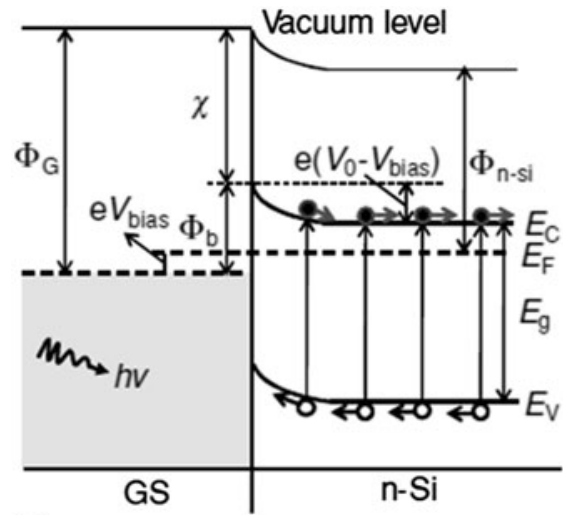

(a)

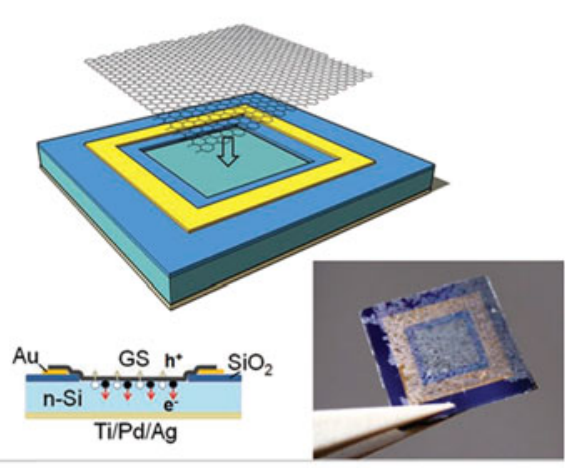

(b)

FIG. 2. (a) The band diagram of a graphene/n-Si Schottky junction; (b) schematic illustration of the fabrication process of graphene/n-Si Schottky junction solar cells. Reprinted with permission from John Wiley and Sons. ${ }^{40}$

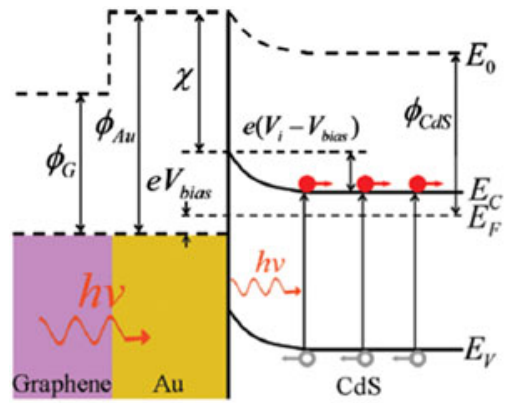

(a)

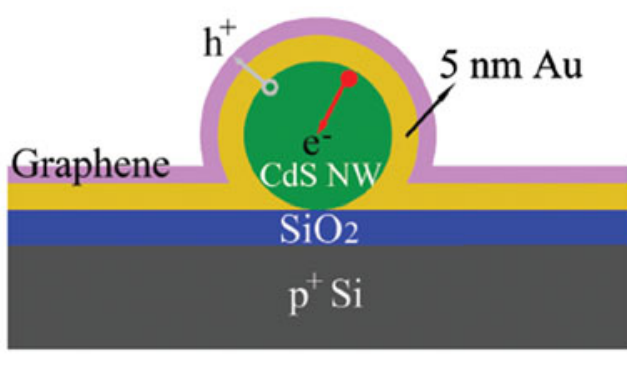

(b)

FIG. 3. (a) Schematic representation of a graphene/CdS NW Schottky junction solar cell; (b) the band diagram of the graphene/CdS NW Schottky junction. Reprinted with permission from American Chemical Society. ${ }^{41}$ 

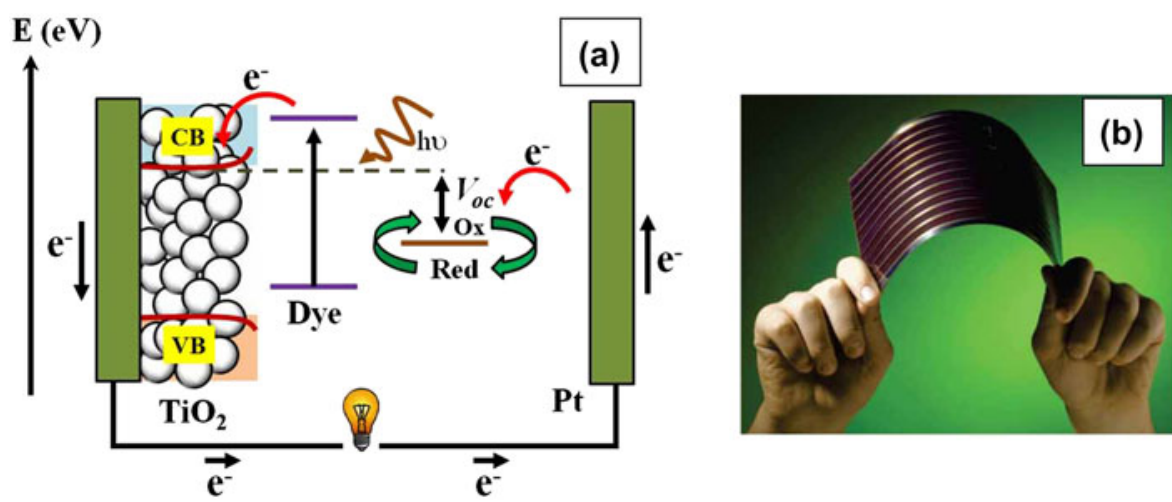

FIG. 4. (a) Schematic structure of DSSCs; (b) sandwich flexible DSC module. Reprinted with permission from American Chemical Society. ${ }^{47}$

of the molecular dye under irradiation leads to a rapid electron injection into the conduction band (CB) of a semiconductor (i.e., $\mathrm{TiO}_{2}$ ), followed by electron transfer to the photoelectrode, where the original state of the dye is regenerated by electron donation from the electrolyte. The collected electrons in the photoelectrode are transported through an external circuit to the counter electrode (CE), and the circuit is completed through regenerating the electrolyte at the CE. ${ }^{47}$ Recently, research has accelerated on optimizing material counterparts (photoanodes, electrolytes, sensitizers, and CEs) to improve the efficiency and stability of DSSCs to bring into commercialization [Fig. 4(b)].

\section{Graphene as photoanode}

Over the last few years, graphene incited great deal of attention in DSSCs owing to their unique characteristics such as (i) rapid electron transport, (ii) exemplary light transmittance capability, and (iii) tunable electrochemical properties. ${ }^{31,48-51} \mathrm{~A}$ wide research has been conducted on graphene-based DSSCs, and they are categorized in Fig. 5. ${ }^{10,21,52-69}$ Wang et al. ${ }^{21}$ explored graphene as a high transmittance electrode material (97.7\%), which is the maiden attempt that opened a new pathway for utilizing graphene in DSSCs [Fig. 5(a)]. In principle, the photoanode of a DSSC functions as an electron "vehicle" to transport the injected electrons from the excited dye sensitizers to the outer circuit. In this point of view, graphene is a promising composite candidate to $\mathrm{TiO}_{2}$, which markedly facilitates the electron transfer from $\mathrm{TiO}_{2}$ to a current collector ${ }^{62,68,70}$ [auxiliary transport indicated in blue color arrow in Fig. 5(b)]. The reason behind it is the band position of graphene [normal hydrogen electrode (NHE) $\sim-4.4 \mathrm{eV}]$, which lies between the fluorine doped tin oxide (FTO) $(\mathrm{NHE} \sim-4.7 \mathrm{eV})$ and $\mathrm{TiO}_{2}$ (NHE -4.2). Thus, it is anticipated that placing graphene in between FTO and $\mathrm{TiO}_{2}$ will offer an easy CT pathway to the photoanode. ${ }^{71}$ Compared to other $1 \mathrm{D}$ composite facilitator, spatially well dispersed graphene sheets extend high feasibility with nanocrystalline $\left(\mathrm{TiO}_{2}\right)$ particles. ${ }^{72}$ Moreover, graphene acts as an auxiliary binder $(0.8 \mathrm{wt} \%)$ in making crack-free $\mathrm{TiO}_{2}$ mesoporous thick films without compromising the photoconversion efficiency of the device. $^{73}$

Varieties of techniques have been demonstrated in the fabrication of graphene- $\mathrm{TiO}_{2}$ (GT) composite. The GT composite can be synthesized either by: (i) graphene decorated on $\mathrm{TiO}_{2}$ framework ${ }^{74}$ [Fig. 6(a)] and/or (ii) in situ deposition of $\mathrm{TiO}_{2}$ nanoparticles (NPs) on graphene scaffold [Fig. 6(b)]. ${ }^{77,78}$ By utilizing both presynthesized graphene matrix or $\mathrm{TiO}_{2}$ framework, the GT composite can be achieved through any one of the following techniques: hydrothermal, ${ }^{79-83}$ electrophoretic deposition, ${ }^{22,68}$ microwave-assisted, ${ }^{84}$ spin coating, ${ }^{85}$ and electrospinning. ${ }^{57,86-88}$ Mostly, the GT composite enhances the photocurrent density $\left(J_{\mathrm{SC}}\right)$ of DSSCs compared to bare $\mathrm{TiO}_{2}$ electrode [Fig. 6(c)]. ${ }^{89}$ Enhancement in $J_{\mathrm{SC}}$ is attributed to (i) the optical scattering effect, which leads to red photon harvesting from solar spectrum and (ii) facilitated charge transport at $\mathrm{TiO}_{2} /$ dye interfaces through graphene expressway, which promotes the charge collection at the photoanode. ${ }^{71}$ In literature, few articles reported that the GT composites enhance the $J_{\mathrm{SC}}$ through lowering the charge recombination at $\mathrm{TiO}_{2} /$ dye interfaces ${ }^{69}$; however, Durantini et al. ${ }^{90}$ confirmed that graphene does not shift the CB of $\mathrm{TiO}_{2}$ and neither influence the recombination process. Therefore, $J_{\mathrm{SC}}$ enhancement is mostly associated with light absorption and scattering properties of graphene flakes in the visible region and auxiliary transport in addition to the $\mathrm{TiO}_{2}$ (graphene displays remarkably high electron mobility under ambient conditions $\sim 15,000 \mathrm{~cm}^{2} / \mathrm{V} / \mathrm{s}$ ). Nevertheless, one of the most critical factors in GT photoanode is the graphene composite quantity (wt\%), which directly influences the PCE of the device. It is widely recognized that inclusion of graphene above the optimized $\mathrm{wt} \%$ in $\mathrm{TiO}_{2}$ lowers the device performance. Though, graphene is known to be 


\section{Dye Sensitized Solar Cells}

\section{Band Diagram}

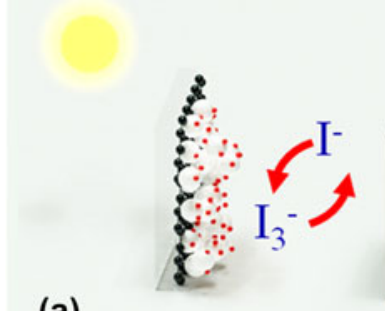

(a)

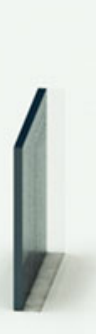

(d)
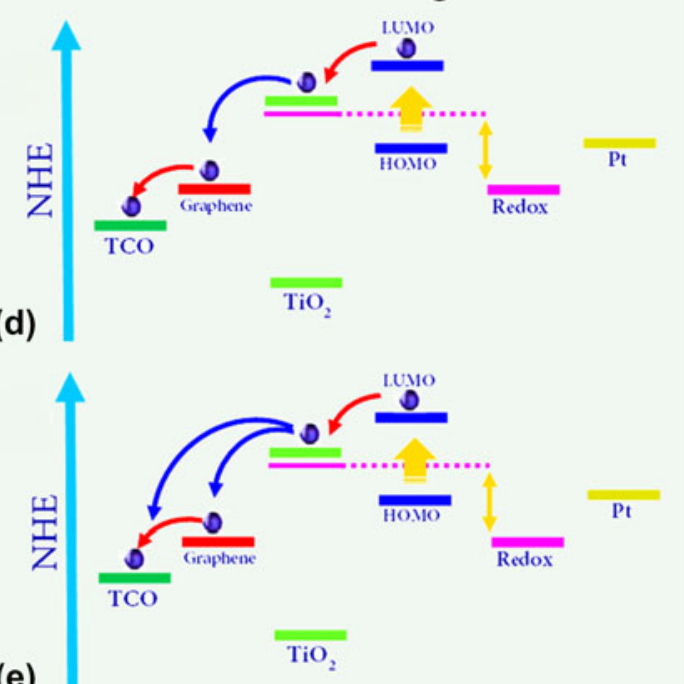

(b)

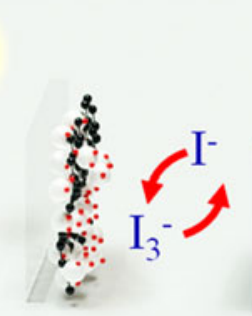

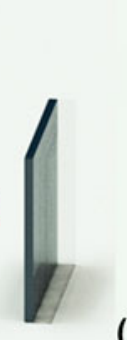

(e)

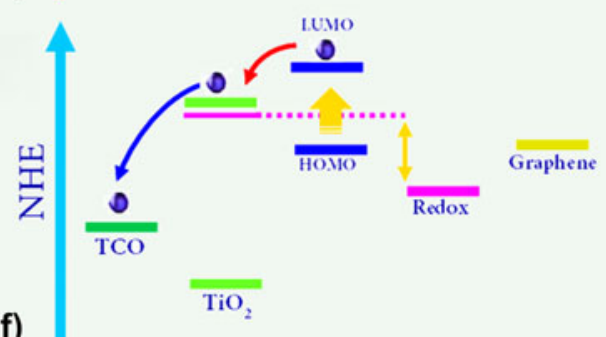

(c)

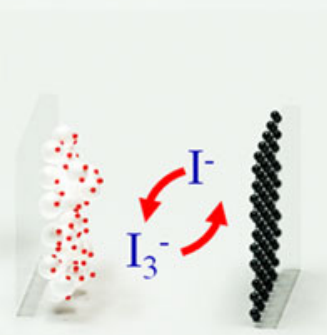

(f)

FIG. 5. Three different DSSCs of (a) graphene as TCO, (b) GT as anode, and (c) graphene as cathode. (d), (e), and (f) represent the corresponding band diagrams of DSSCs shown in (a), (b), and (c) respectively.

transparent in the wave length range of about $200-800 \mathrm{~nm}$, however, more amount of graphene into the $\mathrm{TiO}_{2}$ matrix lowers the light availability for dye molecules, which ultimately decreases the light-harvesting contribution from dye sensitizers. On the other hand, overloading of graphene causes the reduction in the dye-loading amount of the GT electrode. Mostly, the narrow pore size of the GT electrode severely limits the dye-loading quantity. To overcome this issue, conventional 2D GT composite electrodes can be replaced with three dimensional (3D) wide pore graphene structure fabricated by using polystyrene inverse opals $^{52}$ and/or 3D nickel foam ${ }^{76}$ scaffolds. It is anticipated that these 3D GT electrodes offer both high dye loading and electrolyte diffusion. In 3D GT architectures, graphene was incorporated locally into the top layers of the inverse opal structures and then embedded into the $\mathrm{TiO}_{2}$ matrix via posttreatment of the $\mathrm{TiO}_{2}$ precursors [Fig. 6(d)].

It is observed that the local arrangement of graphene sheets in 3D GT effectively enhances the electron transport without reducing light-harvesting contribution from dye molecules. Comparing 2D and 3D GT electrodes, it is found that 3D GT composite improves both $J_{\mathrm{SC}}$ and $V_{\mathrm{OC}}$ unlike 2D GT electrodes. The unprecedented $V_{\mathrm{OC}}$ enhancement is ascribed to the high electrolyte diffusion at wide-pore natured photoanodes, ${ }^{91}$ which ultimately enhances the energy transfer sites and lowers the recombination rate at $\mathrm{TiO}_{2} /$ dye interfaces and thus supports high $V_{\mathrm{OC}}$ in these devices.

\section{Graphene as cathode materials}

In DSSCs, CE is an essential constituent, which injects electrons into the electrolyte to catalyze triiodide reduction $\left(\mathrm{I}_{3}^{-}\right.$to $\left.\mathrm{I}^{-}\right)$after charge injection from the photooxidized dye. The electrocatalytic reduction of $\mathrm{I}_{3}^{-}$to $\mathrm{I}^{-}$at the $\mathrm{CE}$ [as shown in Eq. (3)] dictates the cathodic activity of DSSCs and influences current generation at the photoanode counterpart through dye regeneration. ${ }^{92-96}$

$$
\mathrm{I}_{3}^{-}+2 \mathrm{e}^{-} \rightarrow 3 \mathrm{I}^{-}
$$

Platinum (Pt) is widely used as CEs for DSSCs owing to its excellent catalytic activity and low resistance. However, due to high cost, low abundance, and low chemical inertness, replacing Pt with other materials is becoming a fundamental issue for DSSCs. So far, it has been reported that different forms of carbon materials are quite stable and best alternatives for Pt CEs in DSSCs. ${ }^{97}$ In this context, graphene has several advantages for being 

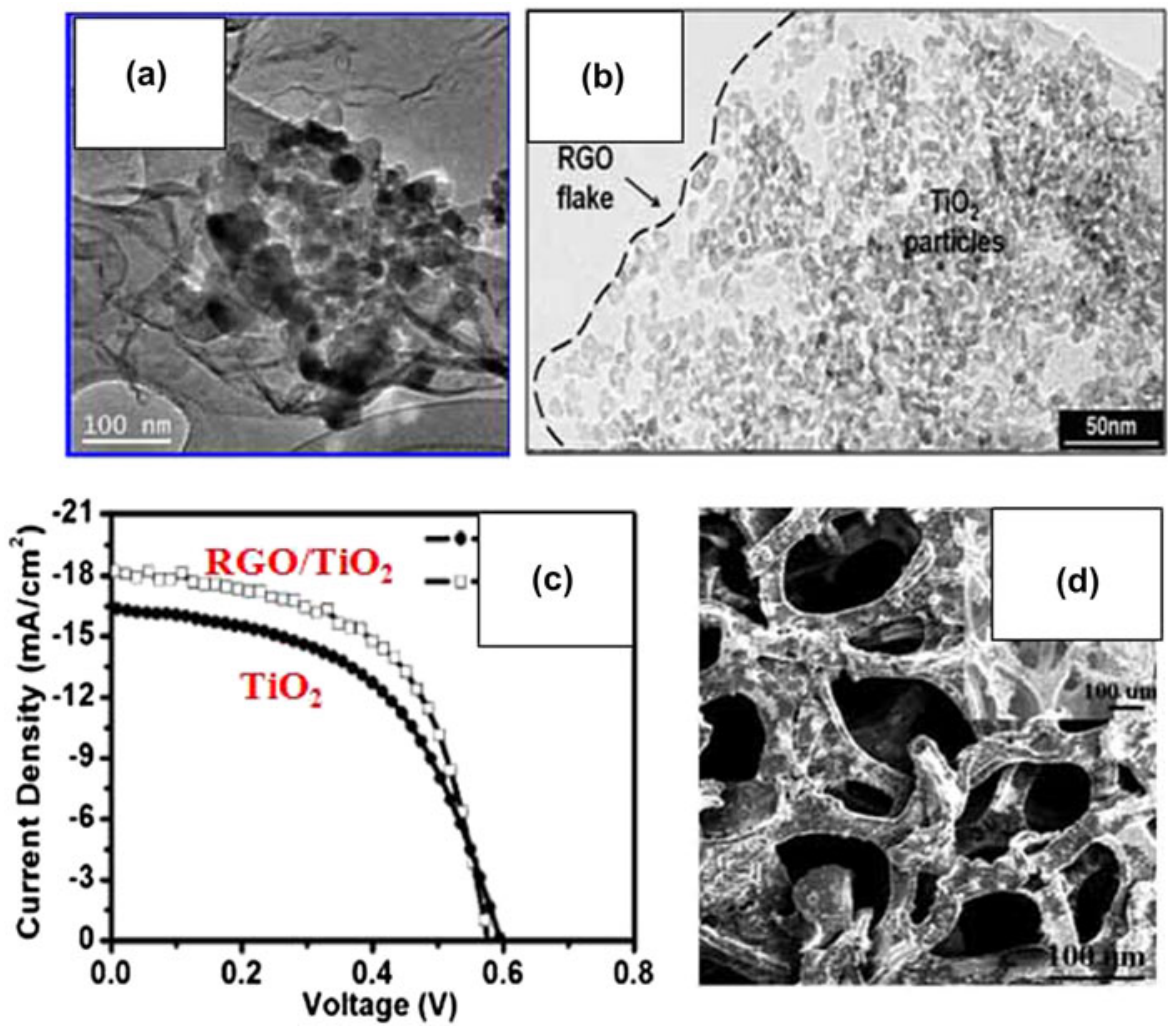

FIG. 6. TEM images of GT composite prepared from different routes (a) graphene@ $\mathrm{TiO}_{2}$; reprinted with permission from American Chemical Society. ${ }^{75}$ (b) $\mathrm{TiO}_{2} @$ graphene. ${ }^{70}$ (c) A comparative photovoltaic performance of DSSC prepared with $\mathrm{TiO}_{2}$ and $\mathrm{rGO}$ TiO ${ }_{2}$-based photoanode; reprinted with permission from John Wiley and Sons. ${ }^{62}$ (d) SEM images of 3D GT composite using Ni foam; reprinted with permission from Elsevier Publisher. ${ }^{76}$

a potential CE material for solar cells: high electrical conductance, high thermal conductivity, ultrahigh transmittance, and excellent mechanical properties. In particular, graphene exhibited remarkable transparency in the entire solar spectrum including IR region. Therefore, graphene CEs are quite advantageous for those types of solar cells/tandem solar cells, which need to absorb the entire range of photon energies (from UV-visible to IR) to generate excitons efficiently. ${ }^{21,33,98,99}$ Furthermore, the high surface area of a 2D graphene sheet $\left(2630 \mathrm{~m}^{2} / \mathrm{g}\right)$, in addition to its intrinsic high transmittance and charge mobility, offers greater versatility as a CE in DSSCs.

Hasin et al. ${ }^{9}$ first reported the triiodide reduction capability of graphene and, thus, demonstrated the wide possibilities for applications in DSSC CEs. The report also showed that the surface functionalization by cationic polymer is one of the promising ways to increase the electrocatalytic property of graphene films, which has numerous advantages over improving DSSC efficiency. Kavan et al. ${ }^{100}$ demonstrated the graphene nanoplateletbased DSSC CE as an optically transparent cathode, which is electrocatalytically active for the $\mathrm{I}_{3}^{-} / \mathrm{I}^{-}$redox reaction. They fabricated the graphene-based cathode using a drop-cast method, and the device showed a PCE of about 5\%. Roy-Mayhew et al. ${ }^{10}$ demonstrated the functionalized graphene sheet as DSSC CE with a PCE of $3.83 \%$. They demonstrated the enhancement of electrocatalytic activity of graphene by functionalizing it using poly(ethylene-oxide)-poly(propylene-oxide)poly(ethylene-oxide) triblock copolymer. In this context, Das et al. ${ }^{31}$ showed the functionalization of large-scale CVD graphene using fluorine ( $\mathrm{F}^{-}$ions) ions with higher catalytic activity toward triiodide reduction compared to pristine graphene. The PCE of the DSSC showed $\sim 2.56 \%$ with corresponding $V_{\mathrm{OC}}, J_{\mathrm{SC}}$, and $\mathrm{FF}$ of $0.66 \mathrm{mV}, 10.9 \mathrm{~mA} / \mathrm{cm}^{2}$, and $35.9 \%$ respectively [Figs. $7(\mathrm{j})-7(\mathrm{n})] .{ }^{31}$ Similarly, $\mathrm{HNO}_{3}$-doped graphene showed an enhancement in the electrocatalytic activities of graphene with a DSSC efficiency of $\sim 3.21 \%$ as shown in Figs. 7(f)-7(i). The cell performance is lower than that expected, and this is due to the lower FF, which causes potential voltage drop at the graphene/FTO interface. Therefore, it has been well demonstrated that functionalized graphene is more effective than pristine graphene to enhance the kinetics of $\mathrm{I}_{3}^{-}$reduction at cathode. As described in Ref. 54, graphene's electrocatalytic activity strongly varies with its defect concentration and oxygen-containing functional groups as shown in Fig. 8. Similarly, electro-catalytic 


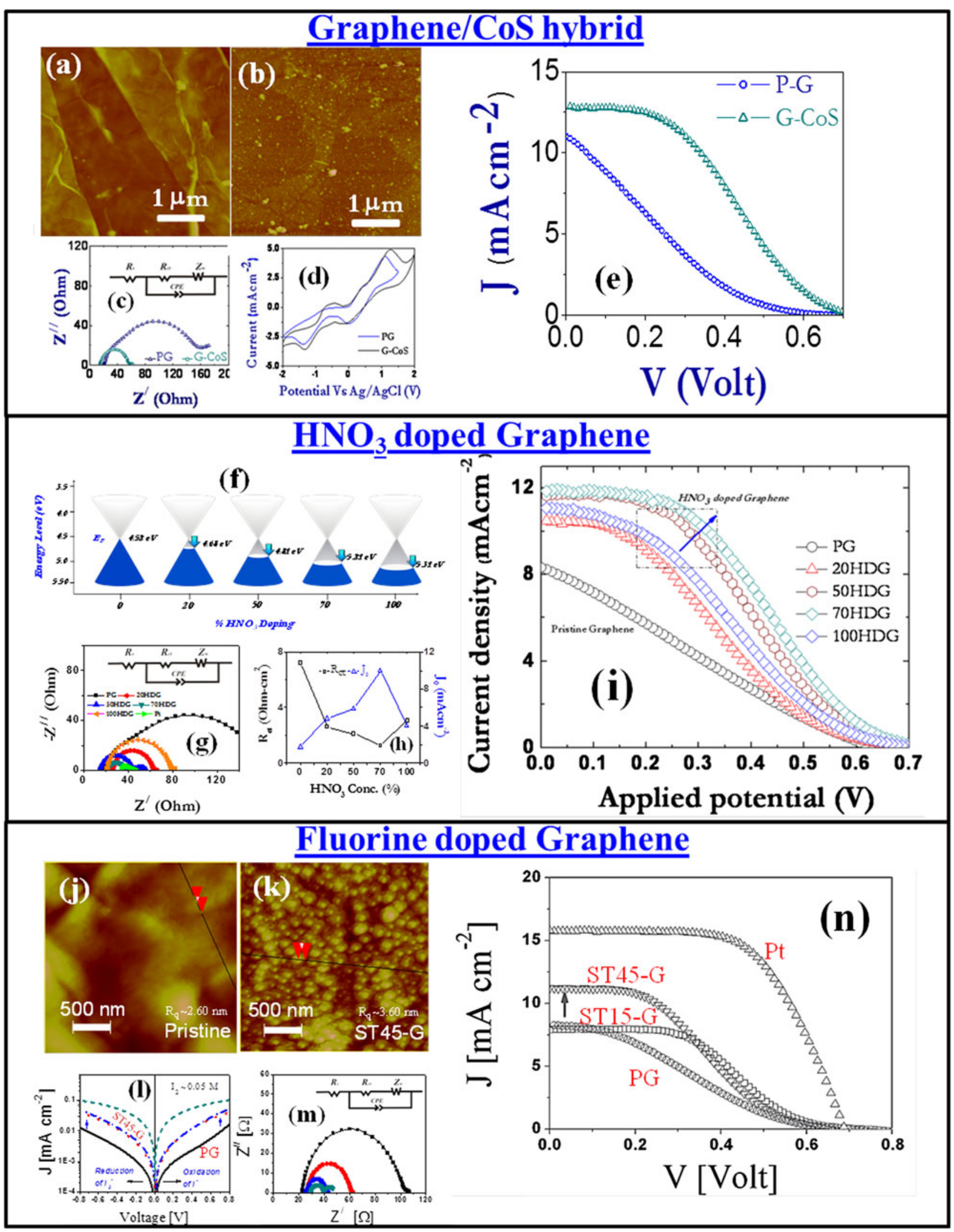

FIG. 7. Graphene synergistic CEs for DSSCs. (a-e) graphene-CoS hybrid electrodes; reprinted with permission from Elsevier Publisher. ${ }^{101}$ (f-i) $\mathrm{HNO}_{3}$-doped graphene; reprinted with permission from Royal Society of Chemistry. ${ }^{102}$ (j-n) Fluorine-doped graphene; reprinted with permission from John Wiley and Sons Publisher. ${ }^{31}$ 
activities of graphene are also associated with its active sites, which play a key role in CT at the interface. Few reports showed that the attachment of other functional groups such as $-\mathrm{COOH},-\mathrm{CO},-\mathrm{NHCO}-$ in graphene effectively improves graphene's electronic as well as electrocatalytic properties. ${ }^{102,103}$

Recently, Xue et al. proposed a new graphene-based 3D architecture for DSSC CEs as illustrated in Fig. 9. In this report, 3D graphene oxide foam is doped with nitrogen and used as a CE of DSSC, which showed a PCE of $7.07 \%$.

Likewise, graphene embedded with polymer materials also showed promises for electrocatalytic cathode for DSSC. Several conducting polymers like, poly(3,4-ethylenedioxythiophene):poly(styrene sulfonate) (PEDOT:PSS), polyaniline (PANI) have been used to enhance the electrocatalytic activities as well as the con- ductivity of the graphene/polymer composite. Hong et al. ${ }^{105}$ reported the PEDOT:PSS/graphene composite CE for DSSCs with $4.5 \%$ PCE. In this work, they demonstrated the increment of $J_{\mathrm{SC}}$ of DSSC after addition of a small amount of graphene in PEDOT-PSS, which was attributed to the higher catalyzing ability of graphene for iodine reduction at the CE. ${ }^{105}$ Similarly, the graphene/PEDOT composite flexible electrode was demonstrated by Lee et al. ${ }^{106}$ In their report, they fabricated the graphene/PEDOT $\mathrm{CE}$ on the flexible PET substrate and assembled as DSSC.

The PCE of DSSC without TCO and Pt is 6.26\%, which is almost comparable to DSSC with TCO and $\mathrm{Pt}(\sim 6.68 \%) .{ }^{106}$ Similarly, $\mathrm{MnO}_{2}$-PANI/r-GO composite showed a PCE of $\sim 6.15 \%$ with $V_{\mathrm{OC}}, J_{\mathrm{SC}}$, and FF of about $0.74 \mathrm{mV}, 12.88 \mathrm{~mA} / \mathrm{cm}^{2}$, and $65 \%$ respectively. One recent approach showed that the polydiallyldimethylammonium
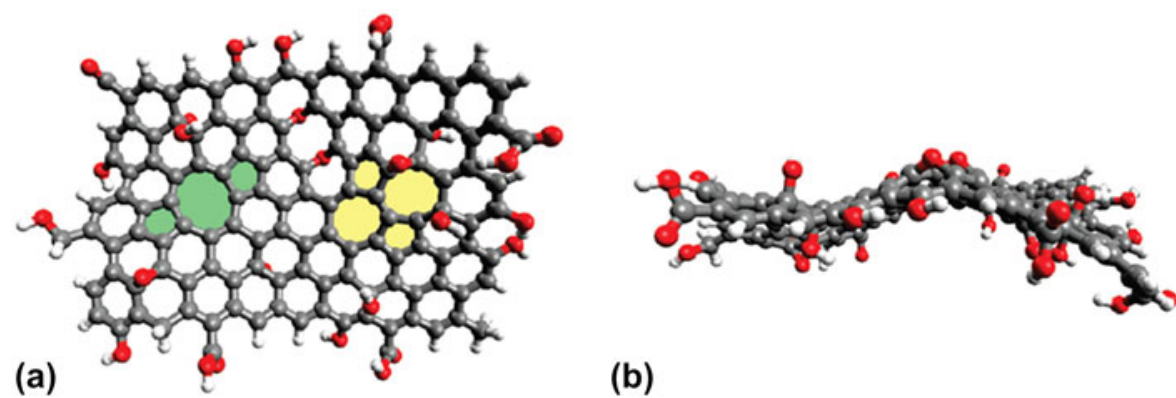

(b)

FIG. 8. (a) and (b) schematic illustrating the attachment of the functional groups in graphene and the incorporation of defects on functionalized graphene sheets. Epoxides and hydroxyls are at the sides of the graphene plane, whereas carbonyl and hydroxyl groups are at the edges (gray atoms: carbon; red atoms: oxygen; and white atoms: hydrogen). Reprinted with permission from American Chemical Society. ${ }^{10}$

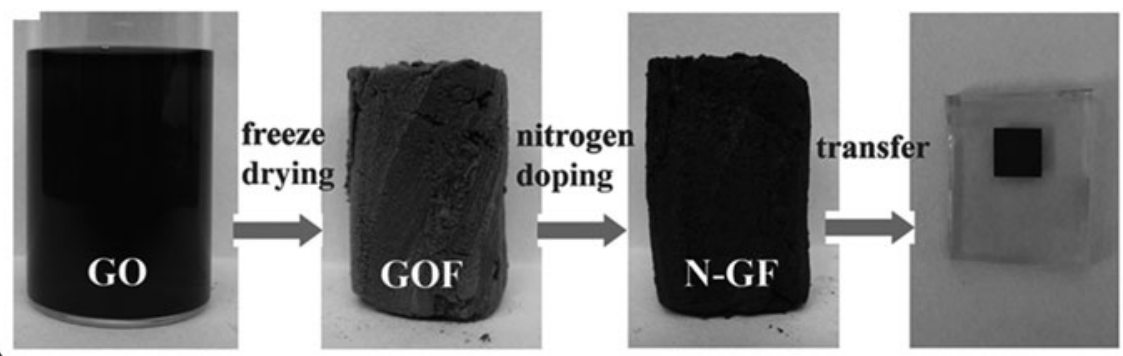

(a)

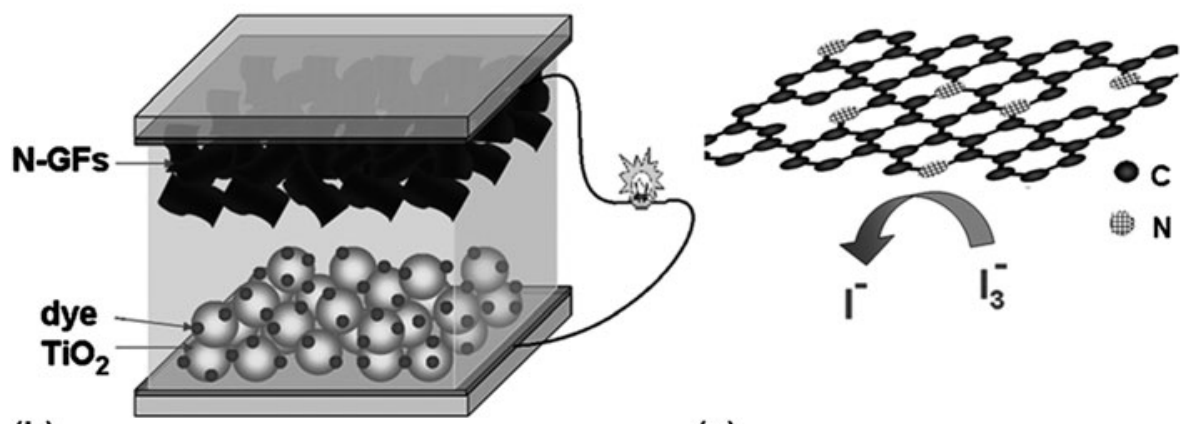

(b)

(c)

FIG. 9. (a) Picture showing the synthesis of N-doped 3D graphene foam and transfer it for DSSC CE; (b) and (c) schematic illustrating the assembly of DSSC using N-doped 3D graphene foam and triiodide reduction process at the CE. Reprinted with permission from John Wiley and Sons. ${ }^{104}$ 
chloride/graphene oxide (PDDA/graphene) composite was used as DSSC CE with $\sim 9.5 \%$ PCE. In this report, Xu et al. fabricated the cationic polymer (PDDA) decorated on negatively charged graphene oxide (GO) by the layer-by-layer assembly method and found enhanced catalytic activity of GO due to the charge disparity between the electronegative carbon atoms and the nitrogen of ammonium ions.

On the other hand graphene/NP composite electrodes stipulate the research based on composite cathode toward high-efficiency DSSC. In this course of research, NPs anchored with graphene has also been demonstrated as a composite CE for DSSCs. Pt NP-anchored graphene was demonstrated for enhancing graphene's electrocatalytic activity for triiodide reduction in DSSCs. ${ }^{63,107,108}$ The goal of these studies was to reduce Pt loading in DSSC $\mathrm{CE}$ by incorporating Pt/graphene composite electrodes without affecting its PCE. In this context, one report was found based on graphene/Ag NW composite electrodes with a PCE of $1.61 \% .^{109}$ Nonmetallic NPs such as CoS, $\mathrm{NiO}, \mathrm{Ni}_{12} \mathrm{P}_{5}$, and $\mathrm{TiN}$ have been used to fabricate graphene- based composite electrodes. ${ }^{101,110-112}$ CVD graphene/CoS composite electrodes showed a PCE of $3.42 \%$ with $V_{\mathrm{OC}}$, $J_{\mathrm{SC}}$, and $\mathrm{FF}$ of $\sim 0.72 \mathrm{~V}, \sim 13.0 \mathrm{~mA} / \mathrm{cm}^{2}$, and $36.40 \%$, respectively. ${ }^{101}$ Das et al. ${ }^{101}$ demonstrated that implantation of CoS NPs on graphene enhanced catalytic activities of the composite electrodes due to the formation of catalytically active triple junction sites, which further facilitates the CT reactions at the DSSC cathode [Figs. 7(a)-7(e)]. Similarly, Wen et al. ${ }^{112}$ showed the graphene/TiN NP composite electrodes for effective DSSC cathode with a PCE up to $5.78 \%$. On the other hand, graphene/CNTs also showed high promises as catalytic electrodes for triiodide reduction in DSSCs, hence, demonstrated in recent reports. ${ }^{113-115}$ Table I lists the details about the performances of DSSCs based on graphene and graphene-derived CE.

\section{Graphene-based quantum dot-sensitized solar cells}

Apart from DSSCs, semiconductor quantum dots (QDs) as light absorbing materials in QD-sensitized solar cells

TABLE I. Characteristics of DSSCs based on graphene CEs.

\begin{tabular}{|c|c|c|c|c|c|c|}
\hline & Synthesis process & $V_{\mathrm{OC}}(\mathrm{V})$ & $J_{\mathrm{SC}}\left(\mathrm{mA} / \mathrm{cm}^{2}\right)$ & $\mathrm{FF}(\%)$ & $\operatorname{PCE}(\%)$ & Ref \\
\hline \multicolumn{7}{|l|}{ Graphene CEs } \\
\hline Graphene nanoplatelets & Commercially available & 0.724 & 13.10 & 0.52 & 5.00 & 100 \\
\hline Graphene & Chemical synthesis process & 0.7 & 1.01 & 36.0 & 0.26 & 21 \\
\hline Graphene oxide & Staudenmaier method & 0.70 & 6.42 & 16.0 & 0.74 & 116 \\
\hline Graphene & Thermally exfoliated & 0.68 & 7.70 & 54.0 & 2.82 & 117 \\
\hline rGO & Chemical synthesis process & 0.75 & 16.99 & 54.0 & 6.81 & 118 \\
\hline rGO & Modified Hummer's method & 0.64 & 6.12 & 56.0 & 2.19 & 119 \\
\hline rGO & Chemical synthesis process & 0.54 & 14.30 & 65.0 & 5.69 & 120 \\
\hline $\mathrm{rGO}$ & Modified Hummer's method & 0.72 & 8.11 & 46.0 & 2.64 & 121 \\
\hline \multicolumn{7}{|l|}{ Functionalized graphene CEs } \\
\hline Oxygen-functionalized graphene & Chemical synthesis & 0.71 & 7.77 & 70.0 & 3.83 & 10 \\
\hline Fluorine-doped graphene & CVD process & 0.66 & 10.9 & 35.9 & 2.56 & 31 \\
\hline $\mathrm{NO}_{3}^{-}$-doped graphene & CVD process & 0.73 & 11.8 & 37.0 & 3.21 & 102 \\
\hline -NHCO- functionalized r-GO & Chemical process & 0.65 & 5.75 & 31.0 & 2.45 & 103 \\
\hline Nitrogen-doped graphene foam & Chemical process & 0.77 & 15.84 & 58.0 & 7.07 & 104 \\
\hline \multicolumn{7}{|l|}{ Graphene composite CEs } \\
\hline Graphene-CoS & CVD process & 0.72 & 12.80 & 36.40 & 3.42 & 101 \\
\hline Graphene-Pt & Chemical synthesis & 0.662 & 11.25 & 52.31 & 3.89 & 108 \\
\hline Graphene/Pt & Thermal exfoliation/chemical synthesis & 0.74 & 6.67 & 59.0 & 2.91 & 63 \\
\hline Graphene-Pt & Chemical synthesis & 0.71 & 15.20 & 71.0 & 7.66 & 107 \\
\hline Carbon-graphene nanocomposite & Chemical synthesis & 0.846 & 7.60 & 77.0 & 9.69 & 122 \\
\hline Graphene- $-\mathrm{Ni}_{12} \mathrm{P}_{5}$ & Hydrothermal reaction process & 0.727 & 12.86 & 61.0 & 5.70 & 111 \\
\hline $\mathrm{rGO}-\mathrm{NiO}$ & Chemical synthesis & 0.67 & 7.53 & 61.0 & 3.06 & 110 \\
\hline rGO-CNTs & Chemical synthesis & 0.75 & 16.05 & 62.7 & 7.55 & 114 \\
\hline rGO-CNTs & Chemical synthesis & 0.76 & 5.60 & 70.0 & 3.00 & 123 \\
\hline Graphene-MWCNT & CVD synthesis & 0.72 & 8.95 & 70.0 & 4.46 & 113 \\
\hline r-GO-MWCNT & Chemical process/CVD grown & 0.75 & 16.05 & 62.7 & 7.55 & 114 \\
\hline r-GO-MWCNT & Chemical synthesis & 0.78 & 12.86 & 61.3 & 6.17 & 115 \\
\hline Graphene-PEDOT & Chemical synthesis & 0.77 & 12.60 & 63.0 & 6.26 & 106 \\
\hline Graphene-PEDOT-PSS & Chemical synthesis & 0.72 & 12.96 & 48.0 & 4.50 & 105 \\
\hline $\begin{array}{l}\text { Graphene oxide and positively charged } \\
\text { poly(diallyldimethylammonium chloride) }\end{array}$ & Chemical synthesis & 0.692 & 18.77 & 74.0 & 9.54 & 124 \\
\hline rGO-PANI & Chemical synthesis & 0.74 & 12.88 & 65.0 & 6.15 & 125 \\
\hline Graphene-Ag NW & Commercially available & 0.55 & 6.45 & 0.52 & 1.61 & 109 \\
\hline Graphene-TiN & Chemical synthesis & 0.728 & 12.34 & 64.33 & 5.78 & 112 \\
\hline
\end{tabular}


(QDSSC) also awake great interest by their fascinating features. In view of tuning the absorption spectrum of semiconductor QDs, ${ }^{126}$ probing the particle size is an efficient way to harvest the entire range of the solar spectrum. ${ }^{127}$ In addition, owing to the unique electronic band structure, QDs can overcome the Shockley-Queisser limit of energy conversion efficiency. ${ }^{128}$ The ability of QDs to harvest hot electrons and to generate multiple carriers makes them a viable candidate for light-harvesting sensitizers in solar cells. ${ }^{129}$ Several semiconductor materials $(\mathrm{CdS}, \mathrm{CdSe}, \mathrm{PbS} \text {, etc. })^{130-135}$ have been used as light sensitizers on wide band gap mesoporous metal oxide layers $\left(\mathrm{TiO}_{2}\right.$ and $\left.\mathrm{ZnO}\right)$ due to their low cost and simple sensitization processing. The device function of QDSCs is analogous to DSSCs [Fig. 10(a)], where the dye molecules are replaced with semiconductor QDs.

Besides, the theoretical efficiency of QDSCs is as high as $44 \%$, the practical performance still lags behind that of DSSCs at present. ${ }^{139}$ Hodes $^{136}$ exclusively compared the critical factors of QDSCs to answer the question, why it is inferior to DSSCs. The main issues in QDSCs are (i) fast electron recombination at surface states of the $\mathrm{TiO}_{2} / \mathrm{QD}$ junction ascribed to a slower electron injection rate from QDs to $\mathrm{TiO}_{2}$ [Fig. 10(b)] and (ii) hole trapping between QDs. To achieve competitive photoconversion efficiency with DSSCs, the above factors have to be bottlenecked in QDSCs. In the context of promoting QDSC performance, different approaches were demonstrated-doping anode, ${ }^{140,141}$ shell layer, ${ }^{142}$ QD passivation, ${ }^{143}$ hierarchical photoanodes, ${ }^{91}$ Pt-free CEs, ${ }^{144}$ panchromatic sensitizers, ${ }^{145}$ etc. However, graphene has attracted growing interest as a potential candidate for improving QDSC performance. Guo et al. ${ }^{137}$ first demonstrated the feasibility of QD-decorated graphene [Fig. 10(c)] as photoelectrode, which showed best incident photon to converted electron (IPCE) compared to QD-decorated CNT scaffold. This confirms graphene as a good candidate for the collection and transport of photogenerated charges, and thus, the layered nanofilm [Fig. 10(d)] provides a new and promising direction toward developing high-performance light-harvesting devices for the next generation solar cells. Following that another interesting approach has been laid, where QD-decorated
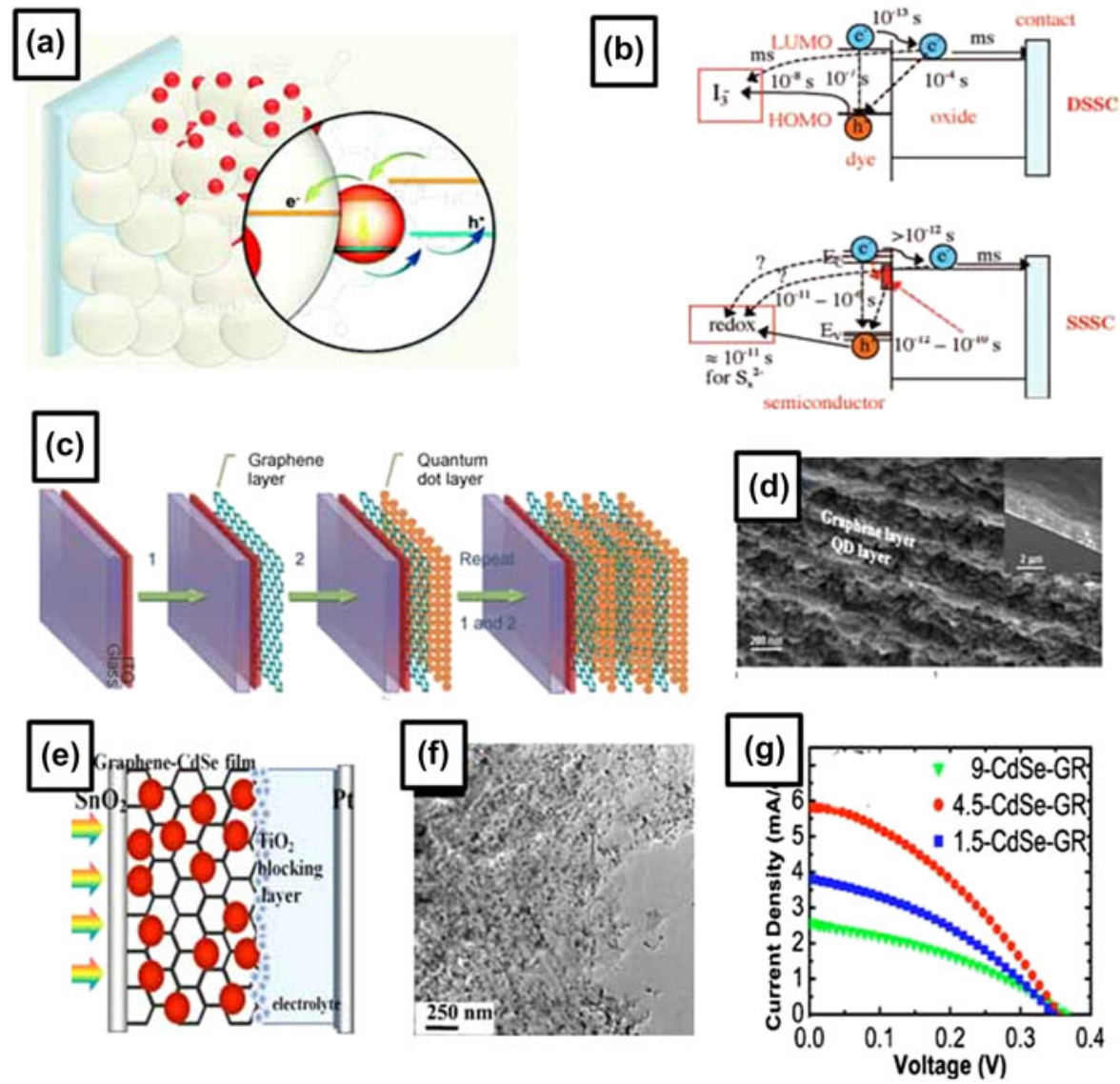

FIG. 10. (a) Schematic of CT at QD-sensitized $\mathrm{TiO}_{2}$ interfaces; reprinted with permission from American Chemical Society. ${ }^{44}$ (b) Comparing CT times for the DSSC (top) and SSSC (bottom); reprinted with permission from American Chemical Society. ${ }^{136}$ (c) Fabrication of the layered graphene/QDs on ITO glass. (d) Cross-sectional SEM image of QD assembly in between the conformal graphene layers ${ }^{137}$; reprinted with permission from John Wiley and Sons. ${ }^{137}$ (e) Schematic structure of QD-assembled graphene as anode layer in QDSCs. ${ }^{138}$ (f) TEM images of CdSe QD-decorated graphene matrix. (g) CdSe QD/graphene JV performance in QDSCs; reprinted with permission from American Institute of Physics. ${ }^{138}$ 
graphene has been applied as a photoanode in QDSC configuration [Figs. 10(e) and 10(f)] resulting in higher photocurrent than individual counterparts of graphene and QD-based device. ${ }^{138}$ This result suggests that the graphene network could serve as a good conducting scaffold to capture and transport photo-induced charge carriers. In addition, the work function of graphene is lower than the $\mathrm{CB}$ of QD CdSe offering energetic arrangement, which favors the photoinduced electron efficiently and transfers from excited CdSe to graphene. Therefore, an excellent conductive network of graphene with large electron transfer rates was obtained to extend electron mean free paths and escape charge recombination, ensuring that electrons can be collected effectively by the TCO substrate to produce photocurrent. Similar phenomena of capturing and trans- porting electrons from CdS QDs to TCO are realized in graphene compared to other carbon nanostructures. ${ }^{146}$

Although QD-decorated few-layer graphene matrix [Figs. 10(c) and 10(d)] showed good QD-graphene contact, the effective loading of the QD sensitizer is limited to a few monolayers. Therefore, careful control of graphene loading is required to extend QD films into the third dimension, where an essential balance must exist between maximizing contact with QDs while minimizing incident light absorption by graphene, which absorbs $\sim 2 \%$ of the incident light per monolayer. Lightcap and Kamat ${ }^{147}$ demonstrate the novel architecture of 3D QD-sensitized graphene photoelectrodes [Fig. 11(a)], which represents a significant step toward overcoming conductivity problems inherent to QD films and opens a new avenue toward improved sensitizer

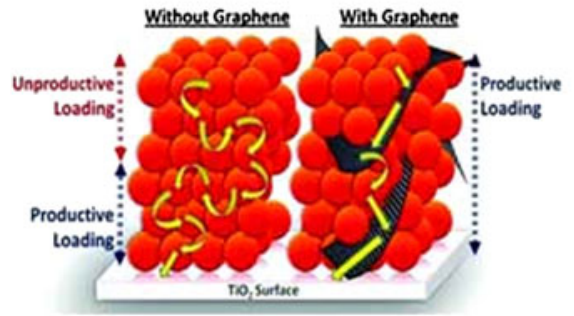

(a)

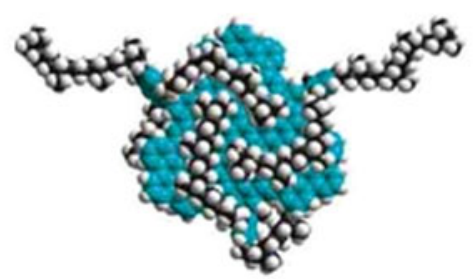

(c)

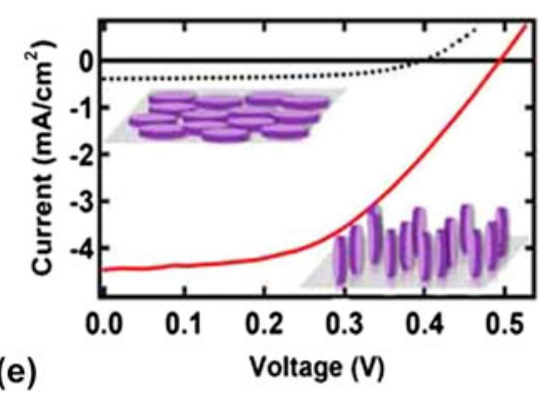

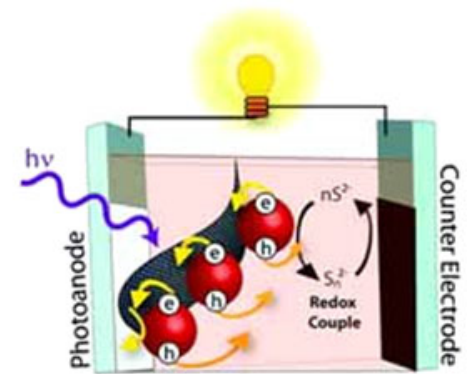

(b)

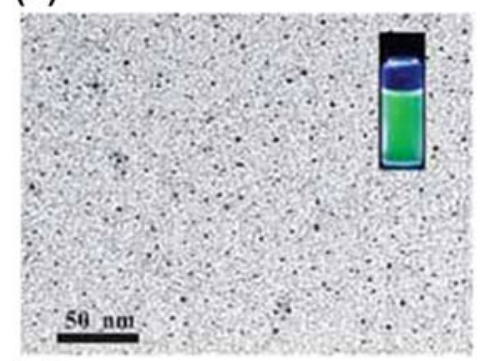

(d)

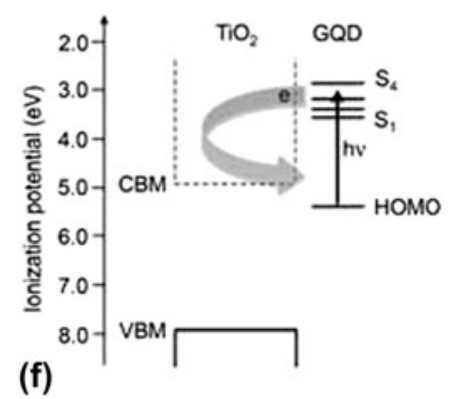

FIG. 11. Schematic illustration of (a) comparing electron transport in QD films with and without graphene layer and (b) QD-graphene compositebased QDSCs; reprinted with permission from American Chemical Society. ${ }^{147}$ (c) Three-dimensional enclosure of the GQD core by the alkyl chains; reprinted with permission from American Chemical Society. ${ }^{148}$ (d) TEM images of green-luminescent GQDs prepared by electrochemical oxidation of a graphene electrode in phosphate buffer solution, and the inset is a photo of a GQD aqueous solution under UV irradiation (365 nm); reprinted with permission from John Wiley and Sons. ${ }^{149}$ (e) $J-V$ performance of GQD-sensitized $\mathrm{TiO}_{2}$ QDSCs with two different GQD orientations (GQDs represented as circular discs). ${ }^{150}$ (f) Energy level diagram of the $\mathrm{C} 132 \mathrm{~A}$ molecule (GQD) on the $\mathrm{TiO}_{2}$ surfaces (VBM, valence band maximum; CBM, $\mathrm{CB}$ minimum); reprinted with permission from American Chemical Society. ${ }^{151}$ 
loading. Furthermore, this device architecture [Fig. 11(b)], displayed improved photocurrent response (150\%) over those prepared without GO attributed to high collection of photogenerated electrons through the GO network in QD-GO composite films, is expected to minimize charge recombination losses at QD grain boundaries.

$\mathrm{Li}$ and $\mathrm{Yan}^{148}$ explored functionalized GQDs as novel sensitizers in mesoscopic solar cells through tuning the band gap from UV to visible light wave length. The expected aggregation of GQDs into graphite was overwhelmed through shielding the graphene from one another by enclosing them in all three dimensions. This is achieved by covalently attaching multiple 1,3,5-trialkyl-substituted phenyl moieties (at the 2-position) to the edges of graphene [Figs. 11(c) and 11(d)]. ${ }^{150}$ The shielded GQDs were demonstrated as sensitizers in triiodide-based DSSC configuration, but it showed a poor $J_{\mathrm{SC}}$ of $200 \mu \mathrm{A} / \mathrm{cm}^{2}$, and a $V_{\mathrm{OC}}$ of $0.48 \mathrm{~V}$ were produced with a fill factor of $0.58 .^{152}$ The much lower current density is attributed to the low affinity of 1 with the oxide surfaces as a result of physical adsorption and the consequent poor charge injection from GQDs to $\mathrm{TiO}_{2}$. Later, the orientation of GQDs (in plane with substrate) were modified as disk-like shapes, and it improves the energy conversion performance [Fig. 11(e)] compared to "face-on" orientation due to higher sensitizer packing density that exists in this structure. ${ }^{150}$ Recently, Williams et al. ${ }^{151}$ studied the possibility of hot electron injection at GQD-anchored single crystal $\mathrm{TiO}_{2}$ (110); this evinces that the graphene nanomaterials have feasibilities of implementing hot carrier solar cells. Nevertheless, the $\mathrm{CB}$ position of $\mathrm{TiO}_{2}$ is close to the HOMO level of GQDs, which allows the recombination of electrons [boomerang effect; arrow indicated in Fig. 11(f)]. Moreover, the graphene nanostructure has to be designed with a size of hundreds of nanometers to micrometers, which can be possible using graphene flakes or graphene nanoribbons. These graphene nanostructures anticipated to serve as the hot carrier chromophore allowing multiple electronic excitations under particular experimental conditions. Therefore, it is anticipated that, by the synergetic approach of hot electron harvesting and minimizing recombination at $\mathrm{TiO}_{2} / \mathrm{GQD}$ interfaces through proper interfacial engineering, GQDs are superficial sensitizers in mesoscopic solar cells. ${ }^{151}$

\section{Graphene-based OPVs}

Recently, OPVs have attracted extensive research and development due to their potential as lightweight, flexible, conformal, and low-cost power sources for various applications. ${ }^{153}$ The working principle of a simple OPV is presented in Fig. 12(a), ${ }^{154}$ which involved many stages for photon-to-electron conversion. First, under light absorption, an electron in the donor undergoes photoinduced excitation forming a Frenkel exciton, and these excitons must diffuse to the donor-acceptor
(D-A) interfaces within the diffusion length to prevent recombining to the ground state. This $\mathrm{D}-\mathrm{A}$ interface concept is analogous in terms of charge transport to a $\mathrm{P}-\mathrm{N}$ junction in an inorganic semiconductor. Subsequently, an exciton at a D-A interface undergoes the $\mathrm{CT}$ process at an ultrafast scale $(\sim 100 \mathrm{fs})$ to form a CT exciton, where the hole and electron remain in the donor and acceptor phases, respectively, held together through columbic attraction. Finally, the CT exciton dissociates, as a result of the builtin electric field, into free holes and electrons, which are then transported through the donor and acceptor phases, respectively, to their respective electrodes. OPVs display as a large-scale transformative solar technology and are made from nontoxic and earth-abundant materials. Despite the high capability in large-scale fabrication, their performance could be improved for commercial applications. Currently OPVs exhibit PCEs of $\sim 8$ to $9 \%$ in prototype cells. ${ }^{160-162}$ Theoretical models suggest that the efficiency could be improved to $>10 \%$ for single cells and $>15 \%$ for tandem cells. To achieve these performance goals, advances in the design of stable device structures are required. In addition, interface engineering also plays a crucial role in determining the performance of OPV devices. To date, graphene-based materials have been utilized as transparent electrodes, ${ }^{156,159,163-165}$ electron acceptors or hole transporters, etc. in view of elevating the performances of OPV devices. Recently, Yong et al. predicted that nanostructured graphene-based photovoltaics can yield higher than $12 \%$ (and $24 \%$ in a stacked structure) [Fig. 12(b)] and strongly recommend applying semiconducting graphene (functionalized graphene) as the photoactive material and metallic graphene (pristine) as the conductive electrodes in OPV devices.

Plenty of research work has been demonstrated on graphene as TCEs, since [Fig. 12(c)] graphene shows high transparency $(>80 \%)$ in a wide window, low sheet resistivity $\left(R_{\mathrm{s}}<100 \Omega / \mathrm{sq}\right)$, and an appropriate work function $(4.5-5.2 \mathrm{eV}) .{ }^{166}$ One of the critical issues in OPVs compared to conventional inorganic solar cells is the charge separation rate at $\mathrm{D}-\mathrm{A}$ interfaces. In the case of inorganic solar cells, the excitons are generated in the form of free electrons and holes, but in OPVs, it generates closely bound electron-hole pairs. Therefore, to separate these closely bound electron-hole pairs, an electron acceptor is essential to the built-in internal field at the interface to break up excitons that diffuse there into free carriers. For making efficient charge separation at D-A interfaces, the electron affinity of the anode layer is larger than that of the donor polymer. Currently, combination of poly(3-hexylthiophene) (P3HT) or poly(3-octylthiophene) (P3OT) with [6,6]-phenyl-C61-butyric acid methyl ester (PCBM) has been utilized as the electron D-A pair in OPVs. However, the fullerene-based PCBM is not necessarily the optimum choice for electron acceptors in view of the relatively low PCE of the OPVs. In view of separating 


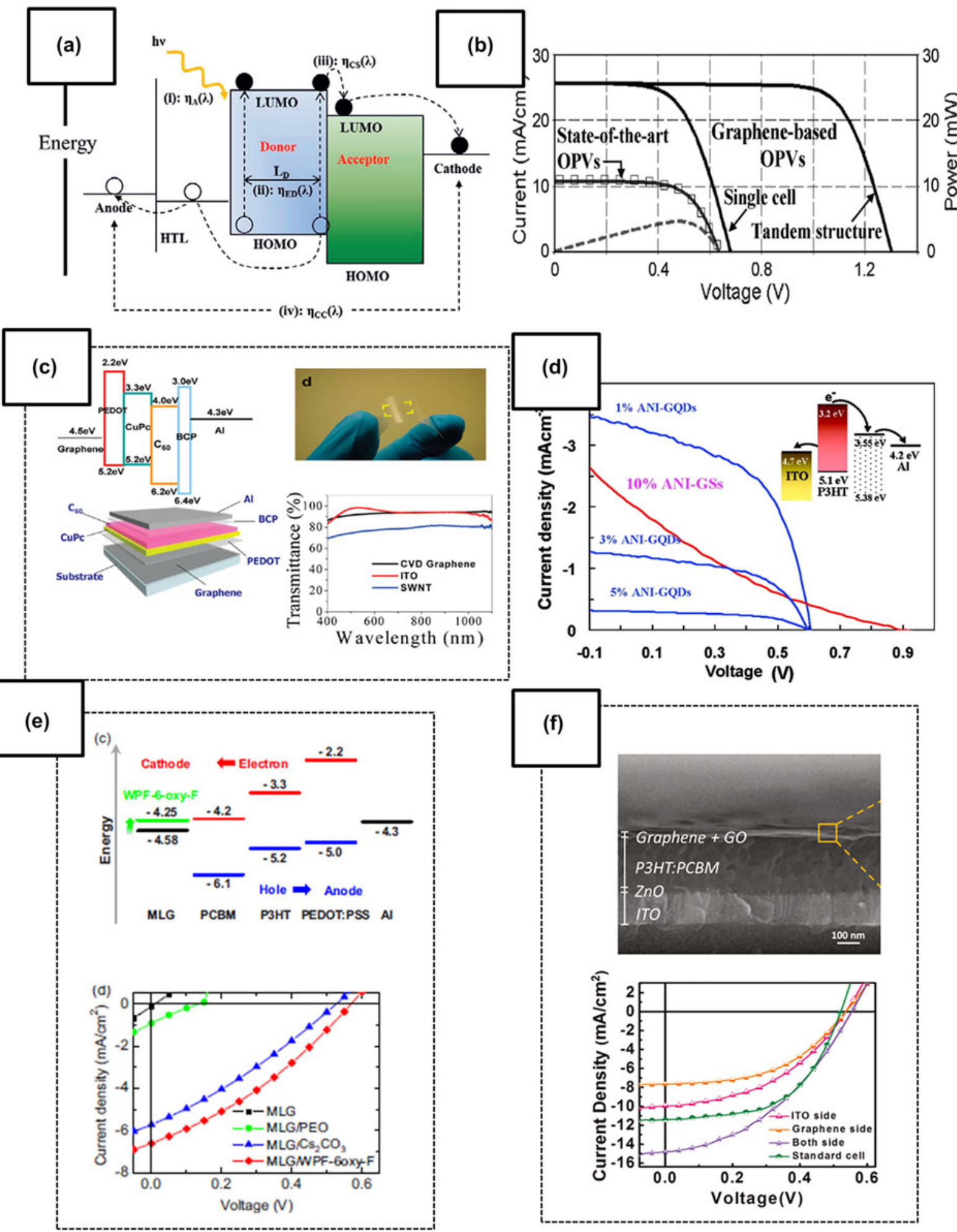

FIG. 12. (a) Mechanism of the photon-to-electron conversion process in bulk heterojunction solar cells; reprinted with permission from Elsevier. ${ }^{154}$ (b) Theoretical efficiency of graphene-based OPV cells proposed by Yong and Tour ${ }^{155}$; reprinted with permission from John Wiley and Sons. (c) Schematic structure of graphene TCE-based OPV shows the corresponding sample photo and transmittance spectra with a band diagram of graphene-based OPV; reprinted with permission from American Chemical Society. ${ }^{156}$ (d) $J-V$ characteristics of the photovoltaic devices based on aniline-functionalized GQDs with different GQD content; reprinted with permission from American Chemical Society. ${ }^{157}$ (e) Energy level diagram of the inverted structure OPV with graphene cathode, $J-V$ characteristics (bottom figure); reprinted with permission from American Institute of Physics. ${ }^{158}$ (f) Cross-sectional SEM image of OPV with graphene cathode layer; $J-V$ characteristics of the semitransparent polymer solar cells consisting of graphene cathodes (bottom image); reprinted with permission from American Chemical Society. ${ }^{159}$ 
electrons at D-A interfaces, graphene can be considered as a promising electron acceptor ${ }^{159,167-173}$ owing to their high charge mobility as high as $7 \times 10^{4} \mathrm{~cm}^{2} / \mathrm{V} / \mathrm{s}$. In addition, due to their high specific surface area for a large interface, high mobility, and tunable band gap, GQDs ${ }^{157}$ exhibit great potential as an electron acceptor material in photovoltaic devices [Fig. 12(d)]. In an OPV device, photoconversion efficiency of the cells governs with the cathode layer, which could satisfy the following properties: (i) to adjust the energetic barrier height between the active layer and the transparent electrodes (it determines the $V_{\mathrm{OC}}$ of the cell) [Fig. 12(e) $]^{158}$ and (ii) to form a selective transporting layer for holes while blocking the electrons. Graphene has been widely applied as a potential cathode layer ${ }^{158,174,175}$ [Fig. 12(f)] in OPVs as is effectively managing the abovementioned properties. Recent reviews by Chen et al. ${ }^{48}$ and Iwan and Chuchmała ${ }^{176}$ contain detailed literature survey on graphene-based polymer solar cells with perspectives and challenges.

\section{SUMMARY AND PERSPECTIVES}

In summary, several processes have been developed for graphene synthesis, and its utilization in different components of next generation solar cells were demonstrated. To date, graphene is applied in solid-state solar cells, DSSCs, QDSCs, and OPVs, owing to its versatile multifunctional properties such as optical, electrical, electrocatalytic, and mechanical properties. Primarily, the unprecedented mechanical property combined with excellent electrical and optical properties fosters graphene as an ideal candidate to replace conventional TCOs in next generation flexible solar cells. Exclusively, graphene offers a wide solar spectrum harvesting (visible to IR range) in a photovoltaic device, which is suitable in panchromatic or tandem solar cells. Therefore, it is anticipated that applying graphene as transparent electrodes will further improve the quantum efficiency of a solar cell, which will further result in the enhancement in cell efficiency. The recent demonstration on hot electron injection possibility from graphene to metal oxide systems encourages graphene as a promising material for highly efficient broadband extraction of light energy into multiple hot-carrier generation. However, current issues with recombination of bound electron-hole pair at graphene/metal oxide $\left(\mathrm{TiO}_{2}\right)$ interface (boomerang effect) can be overwhelmed in near future by inserting shell layer coating (high Fermi level than $\mathrm{TiO}_{2}$ ). It is anticipated that the combination of broadband absorption and hotcarrier multiplication enables graphene to efficiently convert light energy from the full solar spectrum into electricity. In solid-state solar cells, graphene is utilized to form a Schottky junction owing to its flexibility in tuning work function. Besides the effective CT rate of the graphenebased Schottky junction, the following issues have to be addressed: (i) trade-off between conductivity and trans- parency of the graphene, (ii) controlling the sheet resistance and simultaneously modulating the work function of graphene, and (iii) lowering the recombination probability through the existing large quantity of the interface at the graphene-semiconductor interface. One of the effective approaches may reduce the interface states at the graphene-semiconductor interface by depositing an appropriate passivation layer on the semiconductor surface. The research has to be initiated to optimize the suitable passivation material for making a highly efficient graphene Schottky junction, which may open new avenues in nanoelectronics as well as in solid-state solar cells. On the other hand, the defect-induced or -doped graphene (promoting edge-plane sites) exhibits superior catalytic activity compared with pristine graphene and thus offer remarkable application as electrocatalytic CEs in DSSCs. In this context, applying functionalized graphene electrodes to the hybrid solar cells (like DSSCs, QDSCs, and OPVs) improve the interfacial CT kinetics at the electrodeelectrolyte interfaces. Therefore, graphene and graphenederived materials have been widely applied as DSSC photoanode and CE parts. It is appreciated that for the last few years, a significant amount of research has been invested on functionalized graphene (chemical and physical approach). Similarly, this approach can also be extended to QDSCs, since Pt shows poising effect with polysulfide electrolyte, which can be solved by graphene or graphene composite-based CEs. Though graphene extends its superior electrocatalytic property toward triiodide or polysulfide reduction in mesoscopic solar cells (DSSCs and QDSCs), controlled synthesis of graphene (impurity-free from other chemical residues) is necessary.

For future work, controlled synthesis of graphene is necessary, which needs to be free from other chemical residues to achieve extraordinary properties of graphene. In particular, controlling graphene's morphologies, using functionalizations, and optimizing the defect concentration would be more advantageous to achieve superior catalytic activities of graphene. Additionally, massive interfacial engineering is necessary to subjugate interfacial voltage drop and leakage current, which will further improve the FF, current density, and open circuit voltage of graphene-based photovoltaic devices. In this context, owing to its excellent combination of properties, there are still lots of rooms available to open up graphene-based novel device architectures (like tandem solar cells, etc.) for photovoltaic applications.

\section{ACKNOWLEDGMENTS}

The authors acknowledge the support of the WCU (World Class University) program through the Korea Science and Engineering Foundation funded by the Ministry of Education, Science and Technology (Grant No. R31-2008-000-10092) and Engineering Research Center Program (Grant No. 2012-0000591). 


\section{REFERENCES}

1. A.A. Balandin: Thermal properties of graphene and nanostructured carbon materials. Nat. Mater. 10, 569-581 (2011).

2. A.K. Geim and K.S. Novoselov: The rise of graphene. Nat. Mater. 6, 183-191 (2007).

3. S. Das and W. Choi: Graphene synthesis. In Graphene: Synthesis and Applications, Vol. 3, 1st ed.; W. Choi and J-W. Lee eds.; Taylor \& Francis Group: Boca Raton, FL, 2011; pp. 27-63.

4. K.S. Novoselov, A.K. Geim, S.V. Morozov, D. Jiang, Y. Zhang, S.V. Dubonos, I.V. Grigorieva, and A.A. Firsov: Electric field effect in atomically thin carbon films. Science 306, 666-669 (2004).

5. L.M. Viculis, J.J. Mack, and R.B. Kaner: A chemical route to carbon nanoscrolls. Science 299, 1361 (2003).

6. Y. Hernandez, V. Nicolosi, M. Lotya, F.M. Blighe, Z.Y. Sun, S. De, I.T. McGovern, B. Holland, M. Byrne, Y.K. Gun'ko, J.J. Boland, P. Niraj, G. Duesberg, S. Krishnamurthy, R. Goodhue, J. Hutchison, V. Scardaci, A.C. Ferrari, and J.N. Coleman: High-yield production of graphene by liquid-phase exfoliation of graphite. Nat. Nanotechnol. 3, 563-568 (2008).

7. W.S. Hummers and R.E. Offeman: Preparation of graphitic oxide. J. Am. Chem. Soc. 80, 1339 (1958).

8. S.S. Li, K.H. Tu, C.C. Lin, C.W. Chen, and M. Chhowalla: Solution-processable graphene oxide as an efficient hole transport layer in polymer solar cells. ACS Nano 4, 3169-3174 (2010).

9. P. Hasin, M.A. Alpuche-Aviles, and Y.Y. Wu: Electrocatalytic activity of graphene multi layers toward $\mathrm{I}^{-} / \mathrm{I}_{3}{ }^{-}$: Effect of preparation conditions and polyelectrolyte modification. J. Phys. Chem. C 114, 15857-15861 (2010).

10. J.D. Roy-Mayhew, D.J. Bozym, C. Punckt, and I.A. Aksay: Functionalized graphene as a catalytic counter electrode in dye-sensitized solar cells. ACS Nano 4, 6203-6211 (2010).

11. G.L. Li, G. Liu, M. Li, D. Wan, K.G. Neoh, and E.T. Kang: Organo- and water-dispersible graphene oxide-polymer nanosheets for organic electronic memory and gold nanocomposites. J. Phys. Chem. C 114, 12742-12748 (2010).

12. S.Q. Chen and Y. Wang: Microwave-assisted synthesis of a $\mathrm{Co}_{3} \mathrm{O}_{4}$-graphene sheet-on-sheet nanocomposite as a superior anode material for Li-ion batteries. J. Mater. Chem. 20, 9735-9739 (2010).

13. J. Wintterlin and M.L. Bocquet: Graphene on metal surfaces. Surf. Sci. 603, 1841-1852 (2009).

14. J.K. Wassei, M. Mecklenburg, J.A. Torres, J.D. Fowler, B.C. Regan, R.B. Kaner, and B.H. Weiller: Chemical vapor deposition of graphene on copper from methane, ethane and propane: Evidence for bilayer selectivity. Small 8, 1415-1422 (2012).

15. C. Berger, Z.M. Song, T.B. Li, X.B. Li, A.Y. Ogbazghi, R. Feng, Z.T. Dai, A.N. Marchenkov, E.H. Conrad, P.N. First, and W.A. de Heer: Ultrathin epitaxial graphite: 2D electron gas properties and a route toward graphene-based nanoelectronics. J. Phys. Chem. B 108, 19912-19916 (2004).

16. M. Hupalo, E.H. Conrad, and M.C. Tringides: Growth mechanism for epitaxial graphene on vicinal $6 \mathrm{H}-\mathrm{SiC}(0001)$ surfaces: A scanning tunneling microscopy study. Phys. Rev. B 80, 4 (2009).

17. K.V. Emtsev, A. Bostwick, K. Horn, J. Jobst, G.L. Kellogg, L. Ley, J.L. McChesney, T. Ohta, S.A. Reshanov, J. Rohrl, E. Rotenberg, A.K. Schmid, D. Waldmann, H.B. Weber, and T. Seyller: Towards wafer-size graphene layers by atmospheric pressure graphitization of silicon carbide. Nat. Mater. 8, 203-207 (2009).

18. W.A. de Heer, C. Berger, X.S. Wu, P.N. First, E.H. Conrad, X.B. Li, T.B. Li, M. Sprinkle, J. Hass, M.L. Sadowski, M. Potemski, and G. Martinez: Epitaxial graphene. Solid State Commun. 143, 92-100 (2007).

19. E. Kymakis, E. Stratakis, M.M. Stylianakis, E. Koudoumas, and C. Fotakis: Spin coated graphene films as the transparent electrode in organic photovoltaic devices. Thin Solid Films 520, 1238-1241 (2011).

20. H.A. Becerril, J. Mao, Z. Liu, R.M. Stoltenberg, Z. Bao, and Y. Chen: Evaluation of solution-processed reduced graphene oxide films as transparent conductors. ACS Nano 2, 463-470 (2008).

21. X. Wang, L.J. Zhi, and K. Mullen: Transparent, conductive graphene electrodes for dye-sensitized solar cells. Nano Lett. 8, 323-327 (2008).

22. A. Chavez-Valdez, M.S.P. Shaffer, and A.R. Boccaccini: Applications of graphene electrophoretic deposition. A review. J. Phys. Chem. B 117, 1502-1515 (2013).

23. G. Eda, Y-Y. Lin, S. Miller, C-W. Chen, W-F. Su, and M. Chhowalla: Transparent and conducting electrodes for organic electronics from reduced graphene oxide. Appl. Phys. Lett. 92, 233305-233313 (2008).

24. D. Li, M.B. Muller, S. Gilje, R.B. Kaner, and G.G. Wallace: Processable aqueous dispersions of graphene nanosheets. Nat. Nanotechnol. 3, 101-105 (2008).

25. L.J. Cote, F. Kim, and J. Huang: Langmuir-blodgett assembly of graphite oxide single layers. J. Am. Chem. Soc. 131, 1043-1049 (2008).

26. R. Ishikawa, M. Bando, H. Wada, Y. Kurokawa, A. Sandhu, and M. Konagai: Layer-by-layer assembled transparent conductive graphene films for silicon thin-film solar cells. Jpn. J. Appl. Phys. 51, 4 (2012).

27. Y. Zhu, W. Cai, R.D. Piner, A. Velamakanni, and R.S. Ruoff: Transparent self-assembled films of reduced graphene oxide platelets. Appl. Phys. Lett. 95, 103104-103113 (2009).

28. C. Chen, Q-H. Yang, Y. Yang, W. Lv, Y. Wen, P-X. Hou, M. Wang, and H-M. Cheng: Self-assembled free-standing graphite oxide membrane. Adv. Mater. 21, 3007-3011 (2009).

29. J. Kim, L.J. Cote, F. Kim, W. Yuan, K.R. Shull, and J. Huang: Graphene oxide sheets at interfaces. J. Am. Chem. Soc. 132, 8180-8186 (2010).

30. X.S. Li, W.W. Cai, J.H. An, S. Kim, J. Nah, D.X. Yang, R. Piner, A. Velamakanni, I. Jung, E. Tutuc, S.K. Banerjee, L. Colombo, and R.S. Ruoff: Large-area synthesis of high-quality and uniform graphene films on copper foils. Science 324, 1312-1314 (2009).

31. S. Das, P. Sudhagar, V. Verma, D. Song, E. Ito, S.Y. Lee, Y.S. Kang, and W. Choi: Amplifying charge-transfer characteristics of graphene for triiodide reduction in dye-sensitized solar cells. Adv. Funct. Mater. 21, 3729-3736 (2011).

32. X. Li, R. Zhang, W. Yu, K. Wang, J. Wei, D. Wu, A. Cao, Z. Li, Y. Cheng, Q. Zheng, R.S. Ruoff, and H. Zhu: Stretchable and highly sensitive graphene-on-polymer strain sensors. Sci. Rep. 2, 870 (2012). doi: 10.1038/srep00870.

33. V.P. Verma, S. Das, I. Lahiri, and W. Choi: Large-area graphene on polymer film for flexible and transparent anode in field emission device. Appl. Phys. Lett. 96, 203108 (2010). doi: $10.1063 / 1.3431630$.

34. D.H. Wang, J.K. Kim, J.H. Seo, I. Park, B.H. Hong, J.H. Park, and A.J. Heeger: Transferable graphene oxide by stamping nanotechnology: Electron-transport layer for efficient bulk-heterojunction solar cells. Angew. Chem. Int. Ed. 52, 2874-2880 (2013).

35. S. Bae, H. Kim, Y. Lee, X.F. Xu, J.S. Park, Y. Zheng, J. Balakrishnan, T. Lei, H.R. Kim, Y.I. Song, Y.J. Kim, K.S. Kim, B. Ozyilmaz, J.H. Ahn, B.H. Hong, and S. Iijima: Roll-to-roll production of 30-inch graphene films for transparent electrodes. Nat. Nanotechnol. 5, 574-578 (2010).

36. J-H. Chen, C. Jang, S. Xiao, M. Ishigami, and M.S. Fuhrer: Intrinsic and extrinsic performance limits of graphene devices on $\mathrm{SiO}_{2}$. Nat. Nanotechnol. 3, 206-209 (2008).

37. A. Akturk and N. Goldsman: Electron transport and full-band electron-phonon interactions in graphene. J. Appl. Phys. 103, 053702-053708 (2008). 
38. X.S. Li, Y.W. Zhu, W.W. Cai, M. Borysiak, B.Y. Han, D. Chen, R.D. Piner, L. Colombo, and R.S. Ruoff: Transfer of large-area graphene films for high-performance transparent conductive electrodes. Nano Lett. 9, 4359-4363 (2009).

39. I. Lahiri, V.P. Verma, and W. Choi: An all-graphene based transparent and flexible field emission device. Carbon 49 , 1614-1619 (2011).

40. X. Li, H. Zhu, K. Wang, A. Cao, J. Wei, C. Li, Y. Jia, Z. Li, X. Li, and $\mathrm{D}$. Wu: Graphene-on-silicon schottky junction solar cells. Adv. Mater. 22, 2743-2748 (2010).

41. Y. Ye, Y. Dai, L. Dai, Z. Shi, N. Liu, F. Wang, L. Fu, R. Peng, X. Wen, Z. Chen, Z. Liu, and G. Qin: High-performance single CdS nanowire (nanobelt) schottky junction solar cells with Au/graphene schottky electrodes. ACS Appl. Mater. Interfaces 2, 3406-3410 (2010).

42. X. Miao, S. Tongay, M.K. Petterson, K. Berke, A.G. Rinzler, B.R. Appleton, and A.F. Hebard: High efficiency graphene solar cells by chemical doping. Nano Lett. 12, 2745-2750 (2012).

43. S. Tongay, K. Berke, M. Lemaitre, Z. Nasrollahi, D.B. Tanner, A.F. Hebard, and B.R. Appleton: Stable hole doping of graphene for low electrical resistance and high optical transparency. Nanotechnology 22, 425701 (2011).

44. I. Mora-Seró and J. Bisquert: Breakthroughs in the development of semiconductor-sensitized solar cells. J. Phys. Chem. Lett. 1 , 3046-3052 (2010).

45. J.Y. Kim, K. Lee, N.E. Coates, D. Moses, T-Q. Nguyen, M. Dante, and A.J. Heeger: Efficient tandem polymer solar cells fabricated by all-solution processing. Science 317, 222-225 (2007).

46. A. Yella, H-W. Lee, H.N. Tsao, C. Yi, A.K. Chandiran, M.K. Nazeeruddin, E.W-G. Diau, C-Y. Yeh, S.M. Zakeeruddin, and M. Grätzel: Porphyrin-sensitized solar cells with cobalt (II/III)-based redox electrolyte exceed 12 percent efficiency. Science 334, 629-634 (2011).

47. A. Hagfeldt, G. Boschloo, L. Sun, L. Kloo, and H. Pettersson: Dye-sensitized solar cells. Chem. Rev. 110, 6595-6663 (2010).

48. D. Chen, H. Zhang, Y. Liu, and J. Li: Graphene and its derivatives for the development of solar cells, photoelectrochemical, and photocatalytic applications. Energy Environ. Sci. 6, 1362-1387 (2013).

49. H-X. Wang, Q. Wang, K-G. Zhou, and H-L. Zhang: Graphene in light: Design, synthesis and applications of photo-active graphene and graphene-like materials. Small 9, 1266-1283 (2013).

50. W. Tu, Y. Zhou, and Z. Zou: Versatile graphene-promoting photocatalytic performance of semiconductors: Basic principles, synthesis, solar energy conversion, and environmental applications. Adv. Funct. Mater. (2013). doi: 10.1002/adfm.201203547.

51. J. Zhang, F. Zhao, Z. Zhang, N. Chen, and L. Qu: Dimensiontailored functional graphene structures for energy conversion and storage. Nanoscale 5, 3112-3126 (2013).

52. H.N. Kim, H. Yoo, and J.H. Moon: Graphene-embedded $3 \mathrm{D} \mathrm{TiO}$ inverse opal electrodes for highly efficient dye-sensitized solar cells: Morphological characteristics and photocurrent enhancement. Nanoscale 5, 4200-4204 (2013).

53. F. Gong, X. Xu, G. Zhou, and Z.S. Wang: Enhanced charge transportation in a polypyrrole counter electrode via incorporation of reduced graphene oxide sheets for dye-sensitized solar cells. Phys. Chem. Chem. Phys. 15, 546-552 (2013).

54. A. Chavez-Valdez, M.S. Shaffer, and A.R. Boccaccini: Applications of graphene electrophoretic deposition. A review. J. Phys. Chem. B 117, 1502-1515 (2013).

55. S. Morales-Torres, L.M. Pastrana-Martinez, J.L. Figueiredo, J.L. Faria, and A.M. Silva: Design of graphene-based $\mathrm{TiO}_{2}$ photocatalysts: A review. Environ. Sci. Pollut. Res. Int. 19, 3676-3687 (2012).
56. J.S. Lee, H.J. Ahn, J.C. Yoon, and J.H. Jang: Three-dimensional nano-foam of few-layer graphene grown by CVD for DSSC. Phys. Chem. Chem. Phys. 14, 7938-7943 (2012).

57. Z. Peining, A.S. Nair, P. Shengjie, Y. Shengyuan, and S. Ramakrishna: Facile fabrication of $\mathrm{TiO}_{2}$-graphene composite with enhanced photovoltaic and photocatalytic properties by electrospinning. ACS Appl. Mater. Interfaces 4, 581-585 (2012).

58. K.S. Lee, Y. Lee, J.Y. Lee, J.H. Ahn, and J.H. Park: Flexible and platinum-free dye-sensitized solar cells with conductingpolymer-coated graphene counter electrodes. ChemSusChem 5, 379-382 (2012).

59. L. Kavan, J.H. Yum, and M. Gratzel: Graphene nanoplatelets outperforming platinum as the electrocatalyst in co-bipyridinemediated dye-sensitized solar cells. Nano Lett. 11, 5501-5506 (2011).

60. Z. He, G. Guai, J. Liu, C. Guo, J.S. Loo, C.M. Li, and T.T. Tan: Nanostructure control of graphene-composited $\mathrm{TiO}_{2}$ by a one-step solvothermal approach for high performance dye-sensitized solar cells. Nanoscale 3, 4613-4616 (2011).

61. L. Kavan, J.H. Yum, M.K. Nazeeruddin, and M. Gratzel: Graphene nanoplatelet cathode for $\mathrm{Co}(\mathrm{III}) /(\mathrm{II})$ mediated dye-sensitized solar cells. ACS Nano 5, 9171-9178 (2011).

62. J. Song, Z. Yin, Z. Yang, P. Amaladass, S. Wu, J. Ye, Y. Zhao, W.Q. Deng, H. Zhang, and X.W. Liu: Enhancement of photogenerated electron transport in dye-sensitized solar cells with introduction of a reduced graphene oxide- $\mathrm{TiO}_{2}$ junction. Chem. Eur. J. 17, 10832-10837 (2011).

63. R. Bajpai, S. Roy, P. Kumar, P. Bajpai, N. Kulshrestha, J. Rafiee, N. Koratkar, and D.S. Misra: Graphene supported platinum nanoparticle counter-electrode for enhanced performance of dye-sensitized solar cells. ACS Appl. Mater. Interfaces 3, 3884-3889 (2011).

64. L. Kavan, J.H. Yum, and M. Gratzel: Optically transparent cathode for dye-sensitized solar cells based on graphene nanoplatelets. ACS Nano 5, 165-172 (2011).

65. J.D. Roy-Mayhew, D.J. Bozym, C. Punckt, and I.A. Aksay: Functionalized graphene as a catalytic counter electrode in dyesensitized solar cells. ACS Nano 4, 6203-6211 (2010).

66. D.M. Guldi and V. Sgobba: Carbon nanostructures for solar energy conversion schemes. Chem. Commun. 47, 606-610 (2011).

67. D. Wei: Dye sensitized solar cells. Int. J. Mol. Sci. 11, 1103-1113 (2010).

68. Y.B. Tang, C.S. Lee, J. Xu, Z.T. Liu, Z.H. Chen, Z. He, Y.L. Cao, G. Yuan, H. Song, L. Chen, L. Luo, H.M. Cheng, W.J. Zhang, I. Bello, and S.T. Lee: Incorporation of graphenes in nanostructured $\mathrm{TiO}_{2}$ films via molecular grafting for dye-sensitized solar cell application. ACS Nano 4, 3482-3488 (2010).

69. N. Yang, J. Zhai, D. Wang, Y. Chen, and L. Jiang: Twodimensional graphene bridges enhanced photoinduced charge transport in dye-sensitized solar cells. ACS Nano 4, 887-894 (2010).

70. N.J. Bell, Y.H. Ng, A. Du, H. Coster, S.C. Smith, and R. Amal: Understanding the enhancement in photoelectrochemical properties of photocatalytically prepared $\mathrm{TiO}_{2}$-reduced graphene oxide composite. J. Phys. Chem. C 115, 6004-6009 (2011).

71. T. Chen, W. Hu, J. Song, G.H. Guai, and C.M. Li: Interface functionalization of photoelectrodes with graphene for high performance dye-sensitized solar cells. Adv. Funct. Mater. 22, 5245-5250 (2012).

72. B. Tang and G. Hu: Two kinds of graphene-based composites for photoanode applying in dye-sensitized solar cell. J. Power Sources 220, 95-102 (2012).

73. C.Y. Neo and J. Ouyang: Graphene oxide as auxiliary binder for $\mathrm{TiO}_{2}$ nanoparticle coating to more effectively fabricate dyesensitized solar cells. J. Power Sources 222, 161-168 (2013). 
74. S. Sun, L. Gao, and Y. Liu: Enhanced dye-sensitized solar cell using graphene- $\mathrm{TiO}_{2}$ photoanode prepared by heterogeneous coagulation. Appl. Phys. Lett. 96, 083113 (2010).

75. H. Wang, S.L. Leonard, and Y.H. Hu: Promoting effect of graphene on dye-sensitized solar cells. Ind. Eng. Chem. Res. 51, 10613-10620 (2012).

76. B. Tang, G. Hu, H. Gao, and Z. Shi: Three-dimensional graphene network assisted high performance dye sensitized solar cells. J. Power Sources 234, 60-68 (2013).

77. X-Y. Zhang, H-P. Li, X-L. Cui, and Y. Lin: Graphene/TiO nanocomposites: Synthesis, characterization and application in hydrogen evolution from water photocatalytic splitting. J. Mater. Chem. 20, 2801-2806 (2010).

78. X. Xin, X. Zhou, J. Wu, X. Yao, and Z. Liu: Scalable synthesis of $\mathrm{TiO}_{2}$ /graphene nanostructured composite with high-rate performance for lithium ion batteries. ACS Nano 6, 11035-11043 (2012).

79. J.N. Ding, C.T. Yu, N.Y. Yuan, Y.B. Liu, and Y Fan: High-quality GS/TiO2 composite for the photoanode of the dye-sensitized solar cells. In Proceedings of the International Conference on Materials for Renewable Energy \& Environment (ICMREE), May 20-22, 2011; pp. 90-94.

80. A. Gs, S. Nair, S.V. Nair, and S. Vadukumpully: One-pot hydrothermal synthesis of $\mathrm{TiO}_{2}$ /graphene nanocomposites for enhanced visible photocatalysis and photovoltaics. RSC Adv. 3(31), 12933-12938 (2013). doi: 10.1039/c3ra41388h.

81. J. Chang, J. Yang, P. Ma, D. Wu, L. Tian, Z. Gao, K. Jiang, and L. Yang: Hierarchical titania mesoporous sphere/graphene composite, synthesis and application as photoanode in dye sensitized solar cells. J. Colloid Interface Sci. 394, 231-236 (2013).

82. J. Fan, S. Liu, and J. Yu: Enhanced photovoltaic performance of dye-sensitized solar cells based on $\mathrm{TiO}_{2}$ nanosheets/graphene composite films. J. Mater. Chem. 22, 17027-17036 (2012).

83. L. Sun, Z. Zhao, Y. Zhou, and L. Liu: Anatase $\mathrm{TiO}_{2}$ nanocrystals with exposed $\{001\}$ facets on graphene sheets via molecular grafting for enhanced photocatalytic activity. Nanoscale 4, 613-620 (2012).

84. X. Liu, L. Pan, T. Lv, G. Zhu, T. Lu, Z. Sun, and C. Sun: Microwave-assisted synthesis of $\mathrm{TiO}_{2}$-reduced graphene oxide composites for the photocatalytic reduction of $\mathrm{Cr}(\mathrm{vi}) . \mathrm{RSC} A d v$. 1, 1245-1249 (2011).

85. T.H. Tsai, S.C. Chiou, and S.M. Chen: Enhancement of dye-sensitized solar cells by using graphene- $\mathrm{TiO}_{2}$ composites as photoelectrochemical working electrode. Int. J. Electrochem. Sci. 6, 3333-3343 (2011).

86. A. Anish Madhavan, S. Kalluri, D.K. Chacko, T.A. Arun, S. Nagarajan, K.R.V. Subramanian, A. Sreekumaran Nair, S.V. Nair, and A. Balakrishnan: Electrical and optical properties of electrospun $\mathrm{TiO}_{2}$-graphene composite nanofibers and its application as DSSC photo-anodes. RSC Adv. 2, 13032-13037 (2012).

87. X. Zhang, P. Suresh Kumar, V. Aravindan, H.H. Liu, J. Sundaramurthy, S.G. Mhaisalkar, H.M. Duong, S. Ramakrishna, and $\mathrm{S}$. Madhavi: Electrospun $\mathrm{TiO}_{2}$-graphene composite nanofibers as a highly durable insertion anode for lithium ion batteries. J. Phys. Chem. C 116, 14780-14788 (2012).

88. C.H. Kim, B-H. Kim, and K.S. Yang: $\mathrm{TiO}_{2}$ nanoparticles loaded on graphene/carbon composite nanofibers by electrospinning for increased photocatalysis. Carbon 50, 2472-2481 (2012).

89. J. Song, Z. Yin, Z. Yang, P. Amaladass, S. Wu, J. Ye, Y. Zhao, W-Q. Deng, H. Zhang, and X-W. Liu: Enhancement of photogenerated electron transport in dye-sensitized solar cells with introduction of a reduced graphene oxide- $\mathrm{TiO}_{2}$ junction. Chem. Eur. J. 17, 10832-10837 (2011).
90. J. Durantini, P.P. Boix, M. Gervaldo, G.M. Morales, L. Otero, J. Bisquert, and E.M. Barea: Photocurrent enhancement in dyesensitized photovoltaic devices with titania-graphene composite electrodes. J. Electroanal. Chem. 683, 43-46 (2012).

91. H. Han, P. Sudhagar, T. Song, Y. Jeon, I. Mora-Sero, F. Fabregat-Santiago, J. Bisquert, Y.S. Kang, and U. Paik: Three dimensional- $\mathrm{TiO}_{2}$ nanotube array photoanode architectures assembled on a thin hollow nanofibrous backbone and their performance in quantum dot-sensitized solar cells. Chem. Commun. 49, 2810-2812 (2013).

92. M. Gratzel: Photoelectrochemical cells. Nature 414, 338-344 (2001).

93. M. Grätzel: Conversion of sunlight to electric power by nanocrystalline dye-sensitized solar cells. J. Photochem. Photobiol., A 164, 3-14 (2004)

94. J.E. Trancik, S.C. Barton, and J. Hone: Transparent and catalytic carbon nanotube films. Nano Lett. 8, 982-987 (2008).

95. G.R. Li, F. Wang, Q.W. Jiang, X.P. Gao, and P.W. Shen: Carbon nanotubes with titanium nitride as a low-cost counter-electrode material for dye-sensitized solar cells. Angew. Chem. Int. Ed. 49, 3653-3656 (2010).

96. M.K. Wang, A.M. Anghel, B. Marsan, N.L.C. Ha, N. Pootrakulchote, S.M. Zakeeruddin, and M. Gratzel: $\mathrm{CoS}$ supersedes Pt as efficient electrocatalyst for triiodide reduction in dye-sensitized solar cells. J. Am. Chem. Soc. 131, 15976 (2009).

97. T.N. Murakami, S. Ito, Q. Wang, M.K. Nazeeruddin, T. Bessho, I. Cesar, P. Liska, R. Humphry-Baker, P. Comte, P. Pechy, and M. Graetzel: Highly efficient dye-sensitized solar cells based on carbon black counter electrodes. J. Electrochem. Soc. 153, A2255-A2261 (2006).

98. A. Reina, X. Jia, J. Ho, D. Nezich, H. Son, V. Bulovic, M.S. Dresselhaus, and J. Kong: Large area, few-layer graphene films on arbitrary substrates by chemical vapor deposition. Nano Lett. 9, 30-35 (2008).

99. M. Acik, G. Lee, C. Mattevi, M. Chhowalla, K. Cho, and Y.J. Chabal: Unusual infrared-absorption mechanism in thermally reduced graphene oxide. Nat. Mater. 9, 840-845 (2010).

100. L. Kavan, J.H. Yum, and M. Gratzel: Optically transparent cathode for dye-sensitized solar cells based on graphene nanoplatelets. ACS Nano 5, 165-172 (2010).

101. S. Das, P. Sudhagar, S. Nagarajan, E. Ito, S.Y. Lee, Y.S. Kang, and W. Choi: Synthesis of graphene-CoS electro-catalytic electrodes for dye sensitized solar cells. Carbon 50, 4815-4821 (2012).

102. S. Das, P. Sudhagar, E. Ito, D-Y. Lee, S. Nagarajan, S.Y. Lee, Y.S. Kang, and W. Choi: Effect of $\mathrm{HNO}_{3}$ functionalization on large scale graphene for enhanced tri-iodide reduction in dyesensitized solar cells. J. Mater. Chem. 22, 20490-20497 (2012).

103. C. Xu, J. Li, X. Wang, J. Wang, L. Wan, Y. Li, M. Zhang, X. Shang, and Y. Yang: Synthesis of hemin functionalized graphene and its application as a counter electrode in dye-sensitized solar cells. Mater. Chem. Phys. 132, 858-864 (2012).

104. Y. Xue, J. Liu, H. Chen, R. Wang, D. Li, J. Qu, and L. Dai: Nitrogen-doped graphene foams as metal-free counter electrodes in high-performance dye-sensitized solar cells. Angew. Chem. Int Ed. 51, 12124-12127 (2012).

105. W. Hong, Y. Xu, G. Lu, C. Li, and G. Shi: Transparent graphene/ PEDOT-PSS composite films as counter electrodes of dye-sensitized solar cells. Electrochem. Commun. 10, 1555-1558 (2008).

106. K.S. Lee, Y. Lee, J.Y. Lee, J-H. Ahn, and J.H. Park: Flexible and platinum-free dye-sensitized solar cells with conductingpolymer-coated graphene counter electrodes. ChemSusChem 5, 379-382 (2012)

107. F. Gong, H. Wang, and Z-S. Wang: Self-assembled monolayer of graphene/Pt as counter electrode for efficient dye-sensitized solar cell. Phys. Chem. Chem. Phys. 13(39), 17676-17682 (2011). doi: $10.1039 / \mathrm{c} 1 \mathrm{cp} 22542 \mathrm{a}$. 
108. P-J. Li, K. Chen, Y-F. Chen, Z-G. Wang, X. Hao, J-B. Liu, J-R. He, and W-L. Zhang: Low platinum loading PtNPs/graphene composite catalyst with high electrocatalytic activity for dyesensitized solar cells. Chin. Phys. B 21, 118101 (2012).

109. M. Al-Mamun, J-Y. Kim, Y-E. Sung, J-J. Lee, and S-R. Kim: Pt and TCO free hybrid bilayer silver nanowire-graphene counter electrode for dye-sensitized solar cells. Chem. Phys. Lett. 561-562, 115-119 (2013).

110. R. Bajpai, S. Roy, N. Koratkar, and D.S. Misra: NiO nanoparticles deposited on graphene platelets as a cost-effective counter electrode in a dye sensitized solar cell. Carbon 56, 56-63 (2013).

111. Y.Y. Dou, G.R. Li, J. Song, and X.P. Gao: Nickel phosphideembedded graphene as counter electrode for dye-sensitized solar cells. Phys. Chem. Chem. Phys. 14, 1339-1342 (2012).

112. Z. Wen, S. Cui, H. Pu, S. Mao, K. Yu, X. Feng, and J. Chen: Metal nitride/graphene nanohybrids: General synthesis and multifunctional titanium nitride/graphene electrocatalyst. Adv. Mater. 23, 5445-5450 (2011).

113. H. Choi, H. Kim, S. Hwang, M. Kang, D-W. Jung, and M. Jeon: Electrochemical electrodes of graphene-based carbon nanotubes grown by chemical vapor deposition. Scr. Mater. 64, 601-604 (2011).

114. J. Velten, A.J. Mozer, D. Li, D. Officer, G. Wallace, R. Baughman, and A. Zakhidov: Carbon nanotube/graphene nanocomposite as efficient counter electrodes in dye-sensitized solar cells. Nanotechnology 23, 085201 (2012).

115. G. Zhu, L. Pan, T. Lu, T. Xu, and Z. Sun: Electrophoretic deposition of reduced graphene-carbon nanotubes composite films as counter electrodes of dye-sensitized solar cells. J. Mater. Chem. 21, 14869-14875 (2011).

116. L. Wan, S. Wang, X. Wang, B. Dong, Z. Xu, X. Zhang, B. Yang, S. Peng, J. Wang, and C. Xu: Room-temperature fabrication of graphene films on variable substrates and its use as counter electrodes for dye-sensitized solar cells. Solid State Sci. 13, 468-475 (2011).

117. A. Kaniyoor and S. Ramaprabhu: Thermally exfoliated graphene based counter electrode for low cost dye sensitized solar cells. J. Appl. Phys. 109, 124308-124316 (2011).

118. D.W. Zhang, X.D. Li, H.B. Li, S. Chen, Z. Sun, X.J. Yin, and S.M. Huang: Graphene-based counter electrode for dye-sensitized solar cells. Carbon 49, 5382-5388 (2011).

119. C-T. Hsieh, B-H. Yang, and J-Y. Lin: One- and two-dimensional carbon nanomaterials as counter electrodes for dye-sensitized solar cells. Carbon 49, 3092-3097 (2011).

120. H. Choi, H. Kim, S. Hwang, Y. Han, and M. Jeon: Graphene counter electrodes for dye-sensitized solar cells prepared by electrophoretic deposition. J. Mater. Chem. 21, 7548-7551 (2011).

121. R. Cruz, D.A. Pacheco Tanaka, and A. Mendes: Reduced graphene oxide films as transparent counter-electrodes for dyesensitized solar cells. Solar Energy 86, 716-724 2012.

122. M. Stefik, J-H. Yum, Y. Hu, and M. Gratzel: Carbon-graphene nanocomposite cathodes for improved Co(ii/iii) mediated dyesensitized solar cells. J. Mater. Chem. A 1, 4982-4987 (2013).

123. H. Choi, H. Kim, S. Hwang, W. Choi, and M. Jeon: Dye-sensitized solar cells using graphene-based carbon nano composite as counter electrode. Sol. Energy Mater. Sol. Cells 95, 323-325 (2011).

124. X.B. Xu, D.K. Huang, K. Cao, M.K. Wang, S.M. Zakeeruddin, and M. Gratzel: Electrochemically reduced graphene oxide multilayer films as efficient counter electrode for dye-sensitized solar cells. Sci. Rep. 3, 7 (2013).

125. W. Sun, T. Peng, Y. Liu, S. Xu, J. Yuan, S. Guo, and X-Z. Zhao: Hierarchically porous hybrids of polyaniline nanoparticles anchored on reduced graphene oxide sheets as counter electrodes for dye-sensitized solar cells. J. Mater. Chem. A 1, 2762-2768 (2013).

126. P.V. Kamat: Quantum dot solar cells. Semiconductor nanocrystals as light harvesters. J. Phys. Chem. C 112, 18737-18753 (2008).

127. A.M. Smith and S. Nie: Semiconductor nanocrystals: Structure, properties, and band gap engineering. Acc. Chem. Res. 43, 190-200 (2009).

128. W.A. Tisdale, K.J. Williams, B.A. Timp, D.J. Norris, E.S. Aydil, and X-Y. Zhu: Hot-electron transfer from semiconductor nanocrystals. Science 328, 1543-1547 (2010).

129. O.E. Semonin, J.M. Luther, S. Choi, H-Y. Chen, J. Gao, A.J. Nozik, and M.C. Beard: Peak external photocurrent quantum efficiency exceeding $100 \%$ via MEG in a quantum dot solar cell. Science $\mathbf{3 3 4}$ 1530-1533 (2011).

130. B. Farrow and P.V. Kamat: CdSe quantum dot sensitized solar cells. Shuttling electrons through stacked carbon nanocups. J. Am. Chem. Soc. 131, 11124-11131 (2009).

131. H. Lee, M. Wang, P. Chen, D.R. Gamelin, S.M. Zakeeruddin, M. Gratzel, and M.K. Nazeeruddin: Efficient CdSe quantum dotsensitized solar cells prepared by an improved successive ionic layer adsorption and reaction process. Nano Lett. 9, 4221-4227 (2009).

132. H.J. Lee, P. Chen, S.J. Moon, F. Sauvage, K. Sivula, T. Bessho, D.R. Gamelin, P. Comte, S.M. Zakeeruddin, S.I. Seok, M. Gratzel, and M.K. Nazeeruddin: Regenerative PbS and CdS quantum dot sensitized solar cells with a cobalt complex as hole mediator. Langmuir 25, 7602-7608 (2009).

133. S. Ruhle, M. Shalom, and A. Zaban: Quantum-dot-sensitized solar cells. ChemPhysChem 11, 2290-2304 (2010).

134. M. Samadpour, S. Gimenez, A.I. Zad, N. Taghavinia, and I. Mora-Sero: Easily manufactured $\mathrm{TiO}_{2}$ hollow fibers for quantum dot sensitized solar cells. Phys. Chem. Chem. Phys. 14, 522-528 (2012)

135. N. Zhou, Y. Yang, X. Huang, H. Wu, Y. Luo, D. Li, and Q. Meng: Panchromatic quantum-dot-sensitized solar cells based on a parallel tandem structure. ChemSusChem 6, 687-692 (2013).

136. G. Hodes: Comparison of dye- and semiconductor-sensitized porous nanocrystalline liquid junction solar cells. J. Phys. Chem. C 112, 17778-17787 (2008).

137. C.X. Guo, H.B. Yang, Z.M. Sheng, Z.S. Lu, Q.L. Song, and C.M. Li: Layered graphene/quantum dots for photovoltaic devices. Angew. Chem. Int. Ed. 49, 3014-3017 (2010).

138. S. Sun, L. Gao, Y. Liu, and J. Sun: Assembly of CdSe nanoparticles on graphene for low-temperature fabrication of quantum dot sensitized solar cell. Appl. Phys. Lett. 98, 093112 (2011). doi: 10.1063/ 1.3558732 .

139. I. Mora-Seró, S. Giménez, F. Fabregat-Santiago, R. Gómez, Q. Shen, T. Toyoda, and J. Bisquert: Recombination in quantum dot sensitized solar cells. Acc. Chem. Res. 42, 1848-1857 (2009).

140. J.W. Lee, D.Y. Son, T.K. Ahn, H.W. Shin, I.Y. Kim, S.J. Hwang, M.J. Ko, S. Sul, H. Han, and N.G. Park: Quantum-dot-sensitized solar cell with unprecedentedly high photocurrent. Sci. Rep. 3, 1050 (2013). doi: 10.1038/srep01050.

141. P. Sudhagar, K. Asokan, E. Ito, and Y.S. Kang: N-ion-implanted $\mathrm{TiO}_{2}$ photoanodes in quantum dot-sensitized solar cells. Nanoscale 4, 2416-2422 (2012)

142. Z. Tachan, I. Hod, M. Shalom, L. Grinis, and A. Zaban: The importance of the $\mathrm{TiO}_{2}$ /quantum dots interface in the recombination processes of quantum dot sensitized solar cells. Phys. Chem. Chem. Phys. 15, 3841-3845 (2013).

143. M.S. De La Fuente, R.S. Sánchez, V. González-Pedro, P.P. Boix S.G. Mhaisalkar, M.E. Rincón, J. Bisquert, and I. Mora-Seró: Effect of organic and inorganic passivation in quantum-dot-sensitized solar cells. J. Phys. Chem. Lett. 4, 1519-1525 (2013).

144. P. Sudhagar, E. Ramasamy, W-H. Cho, J. Lee, and Y.S. Kang: Robust mesocellular carbon foam counter electrode for 
quantum-dot sensitized solar cells. Electrochem. Commun. 13 34-37 (2011).

145. A. Braga, S. Giménez, I. Concina, A. Vomiero, and I. Mora-Seró: Panchromatic sensitized solar cells based on metal sulfide quantum dots grown directly on nanostructured $\mathrm{TiO}_{2}$ electrodes. J. Phys. Chem. Lett. 2, 454-460 (2011).

146. J. Zhao, J. Wu, F. Yu, X. Zhang, Z. Lan, and J. Lin: Improving the photovoltaic performance of cadmium sulfide quantum dots-sensitized solar cell by graphene/titania photoanode. Electrochim. Acta 96, 110-116 (2013).

147. I.V. Lightcap and P.V. Kamat: Fortification of CdSe quantum dots with graphene oxide. Excited state interactions and light energy conversion. J. Am. Chem. Soc. 134, 7109-7116 (2012).

148. L.S. Li and X. Yan: Colloidal graphene quantum dots. J. Phys. Chem. Lett. 1, 2572-2576 (2010).

149. Y. Li, Y. Hu, Y. Zhao, G. Shi, L. Deng, Y. Hou, and L. Qu: An electrochemical avenue to green-luminescent graphene quantum dots as potential electron-acceptors for photovoltaics. Adv. Mater. 23, 776-780 (2011).

150. I.P. Hamilton, B. Li, X. Yan, and L.S. Li: Alignment of colloidal graphene quantum dots on polar surfaces. Nano Lett. 11, 1524-1529 (2011).

151. K.J. Williams, C.A. Nelson, X. Yan, L-S. Li, and X. Zhu: Hot electron injection from graphene quantum dots to $\mathrm{TiO}_{2}$. ACS Nano 7, 1388-1394 (2013).

152. X. Yan, X. Cui, and B. Li, L-S. Li: Large, solution-processable graphene quantum dots as light absorbers for photovoltaics. Nano Lett. 10, 1869-1873 (2010).

153. F.C. Krebs: Fabrication and processing of polymer solar cells: A review of printing and coating techniques. Sol. Energy Mater. Sol. Cells 93, 394-412 (2009).

154. Y-W. Su, S-C. Lan, and K-H. Wei: Organic photovoltaics. Mater. Today 15, 554-562 (2012).

155. V. Yong and J.M. Tour: Theoretical efficiency of nanostructured graphene-based photovoltaics. Small 6, 313-318 (2010).

156. L. Gomez De Arco, Y. Zhang, C.W. Schlenker, K. Ryu, M.E. Thompson, and C. Zhou: Continuous, highly flexible, and transparent graphene films by chemical vapor deposition for organic photovoltaics. ACS Nano 4, 2865-2873 (2010).

157. V. Gupta, N. Chaudhary, R. Srivastava, G.D. Sharma, R. Bhardwaj, and S. Chand: Luminscent graphene quantum dots for organic photovoltaic devices. J. Am. Chem. Soc. 133, 9960-9963 (2011).

158. G. Jo, S.I. Na, S.H. Oh, S. Lee, T.S. Kim, G. Wang, M. Choe, W. Park, J. Yoon, D.Y. Kim, Y.H. Kahng, and T. Lee: Tuning of a graphene-electrode work function to enhance the efficiency of organic bulk heterojunction photovoltaic cells with an inverted structure. Appl. Phys. Lett. 97, 213301 (2010). doi: 10.1063/1.3514551.

159. Y.Y. Lee, K.H. Tu, C.C. Yu, S.S. Li, J.Y. Hwang, C.C. Lin, K.H. Chen, L.C. Chen, H.L. Chen, and C.W. Chen: Top laminated graphene electrode in a semitransparent polymer solar cell by simultaneous thermal annealing/releasing method. ACS Nano 5, 6564-6570 (2011).

160. Z. He, C. Zhong, S. Su, M. Xu, H. Wu, and Y. Cao: Enhanced power-conversion efficiency in polymer solar cells using an inverted device structure. Nat. Photonics 6, 591-595 (2012).

161. L. Dou, J. You, J. Yang, C.C. Chen, Y. He, S. Murase, T. Moriarty, K. Emery, G. Li, and Y. Yang: Tandem polymer solar cells featuring a spectrally matched low-bandgap polymer. Nat. Photonics 6, 180-185 (2012).

162. C.E. Small, S. Chen, J. Subbiah, C.M. Amb, S.W. Tsang, T.H. Lai, J.R. Reynolds, and F. So: High-efficiency inverted dithienogermole-thienopyrrolodione-based polymer solar cells. Nat. Photonics 6, 115-120 (2012).

163. H. Park, P.R. Brown, V. Bulović, and J. Kong: Graphene as transparent conducting electrodes in organic photovoltaics: Studies in graphene morphology, hole transporting layers, and counter electrodes. Nano Lett. 12, 133-140 (2011).

164. P. Lin, W.C.H. Choy, D. Zhang, F. Xie, J. Xin, and C.W. Leung: Semitransparent organic solar cells with hybrid monolayer graphene/metal grid as top electrodes. Appl. Phys. Lett. 102, 113303 (2013). doi: 10.1063/1.4798254.

165. G. Eda, G. Fanchini, and M. Chhowalla: Large-area ultrathin films of reduced graphene oxide as a transparent and flexible electronic material. Nat. Nanotechnol. 3, 270-274 (2008).

166. X. Wan, G. Long, L. Huang, and Y. Chen: Graphene: A promising material for organic photovoltaic cells. Adv. Mater. 23, 5342-5358 (2011).

167. S. Abdulalmohsin and J.B. Cui: Graphene-enriched P3HT and porphyrin-modified $\mathrm{ZnO}$ nanowire arrays for hybrid solar cell applications. J. Phys. Chem. C 116, 9433-9438 (2012).

168. Y.Y. Choi, S.J. Kang, H.K. Kim, W.M. Choi, and S.I. Na: Multilayer graphene films as transparent electrodes for organic photovoltaic devices. Sol. Energy Mater. Sol. Cells 96, 281-285 (2012).

169. C.L. Hsu, C.T. Lin, J.H. Huang, C.W. Chu, K.H. Wei, and L.J. Li: Layer-by-layer graphene/TCNQ stacked films as conducting anodes for organic solar cells. ACS Nano 6, 5031-5039 (2012).

170. S. Lee, J.S. Yeo, Y. Ji, C. Cho, D.Y. Kim, S.I. Na, B.H. Lee, and T. Lee: Flexible organic solar cells composed of P3HT: PCBM using chemically doped graphene electrodes. Nanotechnology 23, 344013 (2012). doi: 10.1088/0957-4484/23/34/344013.

171. Z. Liu, J. Li, Z.H. Sun, G. Tai, S.P. Lau, and F. Yan: The application of highly doped single-layer graphene as the top electrodes of semitransparent organic solar cells. ACS Nano 6, 810-818 (2012).

172. H. Park, R.M. Howden, M.C. Barr, V. Bulović, K. Gleason, and J. Kong: Organic solar cells with graphene electrodes and vapor printed poly(3,4-ethylenedioxythiophene) as the hole transporting layers. ACS Nano 6, 6370-6377 (2012).

173. S. Zhong, J.Q. Zhong, H.Y. Mao, R. Wang, Y. Wang, D.C. Qi, K.P. Loh, A.T.S. Wee, Z.K. Chen, and W. Chen: CVD graphene as interfacial layer to engineer the organic donor-acceptor heterojunction interface properties. ACS Appl. Mater. Interfaces 4, 3134-3140 (2012).

174. H.P. Kim, A.R.B. Mohd Yusoff, and J. Jang: Organic solar cells using a reduced graphene oxide anode buffer layer. Sol. Energy Mater. Sol. Cells 110, 87-93 (2013).

175. H. Park, S. Chang, M. Smith, S. Gradečak, and J. Kong: Interface engineering of graphene for universal applications as both anode and cathode in organic photovoltaics. Sci. Rep. 3, 1581 (2013). doi: 10.1038/srep01581.

176. A. Iwan and A. Chuchmała: Perspectives of applied graphene: Polymer solar cells. Prog. Polym. Sci. 37, 1805-1828 (2012). 